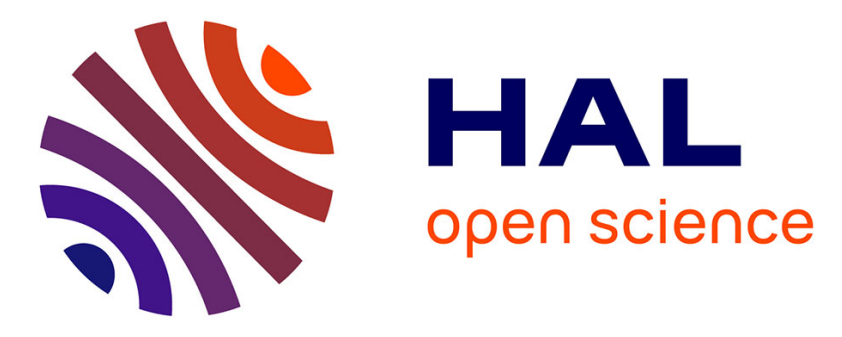

\title{
Enhanced adsorption of methylene blue on chemically modified graphene nanoplatelets thanks to favorable interactions
}

Rabita Mohd Firdaus, Noor Izzati Md Rosli, Jaafar Ghanbaja, Brigitte

Vigolo, Abdul Rahman Mohamed

\section{To cite this version:}

Rabita Mohd Firdaus, Noor Izzati Md Rosli, Jaafar Ghanbaja, Brigitte Vigolo, Abdul Rahman Mohamed. Enhanced adsorption of methylene blue on chemically modified graphene nanoplatelets thanks to favorable interactions. Journal of Nanoparticle Research, 2019, 21 (12), pp.257. 10.1007/s11051019-4701-4 . hal-02612254

\section{HAL Id: hal-02612254 \\ https://hal.science/hal-02612254}

Submitted on 19 May 2020

HAL is a multi-disciplinary open access archive for the deposit and dissemination of scientific research documents, whether they are published or not. The documents may come from teaching and research institutions in France or abroad, or from public or private research centers.
L'archive ouverte pluridisciplinaire HAL, est destinée au dépôt et à la diffusion de documents scientifiques de niveau recherche, publiés ou non, émanant des établissements d'enseignement et de recherche français ou étrangers, des laboratoires publics ou privés. 


\title{
Enhanced adsorption of methylene blue on chemically
}

\section{modified graphene nanoplatelets thanks to favorable}

\section{interactions}

Rabita Mohd Firdaus, ${ }^{a}$ Noor Izzati Md Rosli, ${ }^{a}$ Jaafar Ghanbaja, ${ }^{\mathrm{b}}$ Brigitte Vigolo*b and Abdul Rahman Mohamed*a

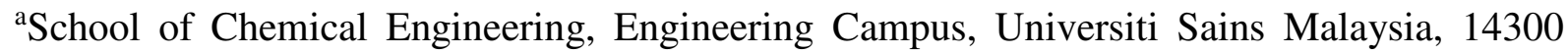
Nibong Tebal, Seberang Perai Selatan, P. Pinang, Malaysia

bInstitut Jean Lamour, CNRS-Université de Lorraine UMR 7198, Campus Artem, 2 allée André Guinier, 54011 Nancy, France

* corresponding authors :

Brigitte.Vigolo@univ-lorraine.fr (B. Vigolo); chrahman@usm.my (A. R. Mohamed)

\begin{abstract}
In the present study, the used graphene nanoplatelets (GNP) are of high structural quality offering the opportunity to modify the adsorbent/adsorbate interactions. Their chemical modification by simple acid oxidation leads to their facile dispersion in water. Morphological, structural and chemical properties of the functionalized GNP are deeply investigated by a set of complementary characterization techniques. The parametric investigation including effects
\end{abstract}


of initial concentration, contact time, solution $\mathrm{pH}$ and temperature of methylene blue (MB) adsorption allows to identify those being relevant for $\mathrm{MB}$ removal enhancement. $\mathrm{MB}$ adsorption is found to increase with contact time, solution temperature and acidic $\mathrm{pH}$. The nature of the MB-GNP interactions and the possible adsorption mechanisms, relatively little understood, are here particularly studied. MB-GNP adsorption is shown to follow a Langmuir isotherm and a pseudo-first-order kinetic model. The adsorption capacity of MB on the chemically modified GNPs $\left(\mathrm{q}_{\mathrm{m}}=225 \mathrm{mg} / \mathrm{g}\right)$ with respect to the external surface is relatively high compared to other carbon nanomaterials. Such adsorbent certainly merits further consideration for removal of other dyes and heavy metals from wastewaters.

Keywords: graphene; functionalization; interactions, adsorption; dye removal

\section{Introduction}

Since more than ten years, many synthesis methods have been developed leading to produce graphenic materials in large volumes (Cheng et al. 2017; Yu et al. 2017; Polat et al. 2015; Novoselov et al. 2012). Especially chemical and mechanical exfoliation of graphite allows to prepare various forms of graphene (Achee et al. 2018). This variety of graphene-based materials offers various and innovative applications which can be now advantageously envisaged with graphene. Environmental applications are especially targeted since added to their high surface area, graphenic materials can be considered as a platform man can chemically modify to generate any specific functionality. Among them depollution by contaminant adsorption has attracted high attention recently. Textile industries consume huge amounts of water and chemicals, particularly in the dyeing and finishing processes. Besides, textile industries focus primarily on colored cloth production and approximately 700,000 tons of dyes 
produced per year are estimated with about $20 \%$ of them are discharged in the effluents (Holkar et al. 2016). Discharge of highly colored synthetic dye waste could be extremely harmful to marine organisms and may even be resistant to natural biological degradation (Holkar et al. 2016; Tahir et al. 2016; Khan and Malik 2014).

Adsorption, particularly using carbon adsorbents, is a promising green decontamination alternative to eliminate the pollutants from wastewaters. The adsorptive properties of functionalized graphene has been shown to depend on its surface area (Hou et al. 2018), functional groups and $\pi$-electron system (Zhou et al. 2016) and porous structure (Gadipelli and Guo 2015). Stability, concentration, and overall quality of the carbon nanomaterial dispersion are also critical for the adsorption process, especially for elimination of organic dyes such as methylene blue (MB) (Johnson et al. 2015) or malachite green (MG) (Robati et al. 2016). Up to now, most of the works on organic dye adsorption by graphenic materials were conducted with graphene oxide (GO) or reduced GO (rGO). Presence of carboxylated-GO within a polyphenylsulfone nanofiltration membrane was shown to enhance heavy metal removal (Shukla et al. 2018). Carboxylated-GO was also efficient to eliminate MB molecules (Zhao et al. 2017). A functionalized GO-based 3D composites was used with an excellent adsorption performance for the removal of mercury ions (Kabiri et al. 2016). Qi et al. stated that polymerbased nanomaterials (polysaccharides/GO) removed well both cationic and anionic organic dyes (Qi et al. 2017). Surface modification of GO with $-\mathrm{SH}$ and $-\mathrm{NH}_{2}$ groups were shown to increase the number of sorption sites and facilitate bonding with heavy metals, thus improving the sorption capacity in the case of MB (Chen et al. 2016). Bradder et al. reported high adsorption capacity of GO for $\mathrm{MB}$ and $\mathrm{MG}$ compared to graphite and activated carbon attributed to electrostatic attraction (Bradder et al. 2011). However, dye molecules are chemically complicated bearing hydrophobic and hydrophilic parts eventually charged depending on the $\mathrm{pH}$. And the nature of dye-adsorbent intercations, which is expected to govern 
the adsorption process and thus adsorption capacity, is usually not well understood. Indeed, because of the various adsorbate/adsorbent systems, the mechanisms playing the major roles in adsorption efficiency are difficult to identify and to generalize to other systems. Control the adsorbent characteristics especially its surface chemistry appears as a key aspect for enhancing the adsorption process and determining the relevant parameters impacting the adsorption effectiveness.

Two main families of graphene commercially available can be mentioned: GO having 2-5 layers and a defected structure due to the numerous functional groups it bears (Dreyer et al. 2014) and graphene flakes or graphene nanoplatelets of often more than 10 layers with a good structural quality (Ermakov et al. 2015; Wei et al. 2009; Stankovich et al. 2006; Ghosh et al. 2010). With the aim of using a well-controlled graphenic material, we have chosen to work with high quality graphene nanoplatelets (GNPs). However, the inertness of this kind of graphenic material is unfavorable to disperse it in aqueous medium. Functionalization is an efficient way to both modify surface properties and induce dispersion of carbon nanomaterials (Georgakilas et al. 2012). In this study, we have applied a simple post-synthesis method to introduce oxygen-containing functional groups onto the sidewalls of GNPs in a controlled manner. The morphological, structural and chemical characteristics of the modified GNPs through functionalization were deeply investigated by means of complementary techniques such as scanning and high-resolution transmission electron microscopy (SEM and HRTEM), thermogravimetric analysis (TGA), Raman, Fourier transform infrared (FTIR) spectroscopy and X-ray photoelectron spectroscopy (XPS). Evaluation of the modified GNPs as a potential adsorbent for the removal of $\mathrm{MB}$ is discussed based on analysis of the adsorption capacity using the Langmuir and Temkin isotherm models. Adsorption capacity of the GNPs is compared to other commonly investigated carbon nanomaterials (including GO, rGO and multi-walled 
carbon nanotubes (MWCNTs)). Efficiency of our modified GNPs to remove MB is found to be relatively high considering the specific surface area they offer.

\section{Materials and chemicals}

The used raw graphene nanoplatelets (referred to as rGNP) was supplied by Universal Science Trading, Malaysia (5 $\mu \mathrm{m}$ particle size, surface area $120-150 \mathrm{~m}^{2} \cdot \mathrm{g}^{-1}$ ). Sulfuric acid, $\mathrm{H}_{2} \mathrm{SO}_{4}$ (96\%), nitric acid, $\mathrm{HNO}_{3}(65 \%)$, ethanol (99\%) and $\mathrm{MB}$, used as pollutant in this study, were purchased from Sigma-Aldrich. Deionized water supplied by USF ELGA water treatment system was used to prepare all the reagents and solutions.

\subsection{Preparation of functionalized GNPs.}

In a typical functionalization experiment, $1 \mathrm{~g}$ of rGNP was placed in a dry, three-neck, roundbottomed flask, with 1:1 mixture of $78 \mathrm{ml}$ of $\mathrm{H}_{2} \mathrm{SO}_{4}$ and $96 \mathrm{~mL}$ of $\mathrm{HNO}_{3}$. Then, the solution was stirred for $16 \mathrm{~h}$ under moderate stirring $(300 \mathrm{rpm})$ at $80^{\circ} \mathrm{C}$. Then the mixture was sonicated in a water bath for $15 \mathrm{~min}$. After that, it was filtered and washed with distilled water until the $\mathrm{pH}$ of the filtrate is neutral. Subsequently, the sample was dried in an oven at $110^{\circ} \mathrm{C}$ for $24 \mathrm{~h}$. This method was repeated for volume ratio of $\mathrm{H}_{2} \mathrm{SO}_{4}$ and $\mathrm{HNO}_{3}$ 1:3 and 3:1. The treated GNP were referred to as fGNP1, fGNP2, and fGNP3 for $\mathrm{H}_{2} \mathrm{SO}_{4} / \mathrm{HNO}_{3}$ ratio of 1:1, 1:3 and 3:1, respectively.

\subsection{Characterization techniques}

HRTEM observations were performed using a JEM-ARM 200F apparatus at $80 \mathrm{kV}$. GNP dispersions in ethanol of the raw and the fGNP were deposited on a holey carbon grid. About 25 images were taken at different locations for each sample in order to guarantee a representative description of the samples. Fast Fourier Transform (FFT) was done on selected areas. SEM of the raw and the functionalized GNP were carried out using an FEI Verios 460L 
tool under extreme high resolution (XHR) with field emission. TGA was performed with a Setaram Setsys evolution 1750. Experiments were performed in dry air (flow rate $20 \mathrm{~mL} . \mathrm{min}^{-}$ ${ }^{1}$ ) as the carrier gas and a temperature ramp of $5{ }^{\circ} \mathrm{C} \cdot \mathrm{min}^{-1}$ from room temperature to $900{ }^{\circ} \mathrm{C}$. For Raman spectroscopy analysis, a Renishaw inVia Raman microscope was used with an excitation wavelength of $632.8 \mathrm{~nm}$, a laser power output of $50 \mathrm{~mW}$ focused on the sample with an x50 objective lens. A range from 100 to $3200 \mathrm{~cm}^{-1}$ of Raman shift was scanned. For each sample, at least 3 spectra were recorded on different areas on the sample deposited on a glass slide. For data analysis, after subtracting a baseline, the intensity of the D or the $\mathrm{G}$ band corresponding to the height at the maximum intensity of the peak is used to calculate the intensity ratio $\mathrm{I}_{\mathrm{D}} / \mathrm{I}_{\mathrm{G}}$. For a direct comparison of the spectrum features, the intensity of the spectra is normalized to that of the $\mathrm{G}$ band.

For Fourier transform infrared spectroscopy, a Model Thermo Fisher Scientific Nicolet iS1O FTIR Spectroscope was used. A Malvern Zetasizer was used to measure the surface charge of the GNP samples. For the preparation of GNP dispersions, the desired amount of the raw or the modified GNP powder (concentration of $1 \mathrm{mg} . \mathrm{L}^{-1}$ ) was dispersed in water using a probe sonicator for $5 \mathrm{~min}$.

The surface area and pore size were evaluated by Brunauer-Emmett-Teller (BET) standard and Barrett-Johner Halenda (BJH) method respectively using an Autosorb 1C Quantachrome analyzer. The BET surface area is also known as the specific surface area (SSA).

For XPS analysis, a Kratos Axis Ultra (Kratos Analytical, U.K.) spectrometer equipped with a monochromatic $\mathrm{Al} \mathrm{K} \mathrm{K}_{\alpha}$ source $(1486.6 \mathrm{eV})$ was used. All spectra were recorded at a $90^{\circ}$ takeoff angle, with the analyzed area being currently about $0.7 \times 0.3 \mathrm{~mm}$. Survey spectra were acquired with $1.0 \mathrm{eV}$ step and $160 \mathrm{eV}$ analyzer pass energy and the high-resolution regions with $0.1 \mathrm{eV}$ step and $20 \mathrm{eV}$ pass energy (instrumental resolution better than $0.5 \mathrm{eV}$ ). Curve fitting was 
performed using a Gaussian/Lorentzian (70/30) peak shape after Shirley's background subtraction and using X-vision 2.2.11 software.

Contact angle goniometer (Model: OCA15plus, DataPhysics) was used to evaluate the hydrophilicity (wettability by water) of the raw and functionalized GNPs. A water droplet (1 $\mu 1)$ was deposited onto the sample surface through a needle tip. A magnified image of water droplet was observed by a digital camera and the contact angle readings were obtained $5 \mathrm{~s}$ after the water drop deposited on the sample surface. For each measurement of contact angle value, at least three points from different parts of the GNP, fGNP1, fGNP2 and fGNP3 were recorded and averaged.

\subsection{Batch equilibrium studies}

Adsorption of MB on the prepared fGNP was performed by batch equilibrium tests. The effects of $\mathrm{MB}$ initial concentration, contact time, solution $\mathrm{pH}$ and temperature on the removal were investigated. The dye solution of few milliliters was taken at regular intervals at every 5 min for 55 min of reaction and analyzed using a UV-vis spectrophotometer (Model Shimadzu UV1800, Japan). The concentration of the treated sample was measured at a wavelength of 665 nm. The removal efficiency $\xi(\%)$ of $\mathrm{MB}$ at period of time, and the equilibrium adsorption capacity $\mathrm{q}_{\mathrm{e}}\left(\mathrm{mg} . \mathrm{g}^{-1}\right)$ were calculated using (1) and (2), respectively:

$$
\begin{array}{ll}
\xi=\frac{\mathrm{C}_{0}-\mathrm{C}_{\mathrm{t}}}{\mathrm{C}_{0}} \times 100 & \text { Eq. (1) } \\
q_{e}=\frac{C_{0}-C_{t}}{W} \times V & \text { Eq. (2) }
\end{array}
$$

Where $\mathrm{C}_{\mathrm{O}}\left(\mathrm{mg} . \mathrm{L}^{-1}\right)$ is the initial MB concentration, $\mathrm{C}_{\mathrm{t}}\left(\mathrm{mg} . \mathrm{L}^{-1}\right)$ is the final concentration of $\mathrm{MB}$ remaining at time $\mathrm{t}, \mathrm{V}(\mathrm{L})$ and $\mathrm{W}(\mathrm{g})$ are the volume of the $\mathrm{MB}$ solution and the weight of the used adsorbent, respectively. 


\subsection{Adsorption isotherm models}

From the Langmuir theory only one dye molecule is adsorbed on each adsorption site to form a monolayer (Han et al. 2017). It is then assumed that once a dye molecule occupies a site, no further adsorption can take place at that site. That means that adsorption mainly occurs on the external surface of the adsorbent having a homogeneous surface and the intermolecular forces rapidly decrease with distance. The Langmuir equation is given by (3):

$$
\frac{C_{e}}{q_{e}}=\frac{1}{K_{L} q_{m}}+\frac{1}{q_{m}} C_{e}
$$

where $q_{e}\left(\mathrm{mg} . \mathrm{g}^{-1}\right)$ is the maximum adsorption capacity, $K_{L}\left(\mathrm{~L}_{\mathrm{mg}} \mathrm{m}^{-1}\right)$ represents the Langmuir isotherm constant and $C_{e}\left(\mathrm{mg} . \mathrm{L}^{-1}\right)$ is the dye concentration at equilibrium. The Langmuir dimensionless separation factor is defined as:

$$
R_{L}=\frac{1}{K_{L} C_{O}}
$$

$\mathrm{R}_{\mathrm{L}}$ indicates the adsorption nature to be either unfavourable if $\mathrm{R}_{\mathrm{L}}>1$, linear if $\mathrm{R}_{\mathrm{L}}=1$, favourable if $0<R_{L}<1$ and irreversible if $R_{L}=0$.

Freundlich model describes adsorption on heterogeneous surfaces following a multilayer adsorption mechanism. It is assumed the stronger binding sites are occupied first and that the binding strength decreases with increasing the degree of site occupation. The Freundlich model equation (5) is;

$$
\log q_{e}=\log K_{F}+\frac{1}{n} \log C_{e}
$$

where $\mathrm{q}_{\mathrm{e}}\left(\mathrm{mg} \cdot \mathrm{g}^{-1}\right)$ is the amount of adsorbate adsorbed per unit mass of adsorbent; $\mathrm{K}_{\mathrm{F}}\left(\mathrm{L} \cdot \mathrm{mg}^{-1}\right)$ is Freundlich isotherm constant. $\mathrm{K}_{\mathrm{F}}$ measures the adsorption capacity of the adsorbent and $1 / \mathrm{n}$ reflects the strength of adsorption in the adsorption process. If value of $1 / n$ is below one, it 
indicates a normal adsorption. On the other hand, $1 / \mathrm{n}$ being above one indicates favorable adsorption conditions (Qiao et al. 2016). $\mathrm{C}_{\mathrm{e}}$ is the equilibrium concentration of the adsorbate $\left(\mathrm{mg} \cdot \mathrm{L}^{-1}\right)$.

Temkin isotherm considers the effect of the adsorbate interaction on the adsorbent based on the uniformly distributed binding energies. It also assumes that the heat of sorption of all the molecules in the layer decreases linearly with coverage due to sorbate/sorbent interactions. The Temkin isotherm equation expressed as (Temkin and Pyzhev 1940). The Temkin model equation is:

$$
\begin{gathered}
q_{e}=B \ln A_{T}+B \ln C_{e} \\
B=\frac{R T}{b_{T}}
\end{gathered}
$$

$\mathrm{A}_{\mathrm{T}}\left(\mathrm{L} \cdot \mathrm{mg}^{-1}\right)$ is the Temkin isotherm equilibrium binding constant $\left(\mathrm{L} . \mathrm{mg}^{-1}\right)$; $\mathrm{b}_{\mathrm{T}}$ is the Temkin isotherm constant, $\mathrm{R}$ the universal gas constant $\left(8.314 \mathrm{~J} \cdot \mathrm{mol}^{-1} \cdot \mathrm{K}^{-1}\right)$ and $\mathrm{B}$ a constant related to heat of sorption $\left(\mathrm{J} \cdot \mathrm{mol}^{-1}\right)$.

\subsection{Adsorption kinetics}

The equation of pseudo first order kinetic model is expressed by the following equation (Lagergren 1898);

$$
\ln \left(q_{e}-q_{t}\right)=\ln q_{e}-k_{1} t
$$

where $\mathrm{q}_{\mathrm{t}}\left(\mathrm{mg} \cdot \mathrm{g}^{-1}\right)$ is amount of adsorbate adsorbed at time $\mathrm{t}$; $\mathrm{q}_{\mathrm{e}}$ is the amount of adsorbate adsorbed at equilibrium (mg. $\mathrm{g}^{-1}$ ) and $\mathrm{k}_{1}$ is pseudo-first-order rate constant of adsorption (min ${ }^{-}$ $\left.{ }^{1}\right)$.

The pseudo second order equation predicts the behaviour over the entire range of adsorption, and it is agreed that an adsorption mechanism being the rate controlling step (McKay and 
Sweeney 1980). The equation of pseudo second order kinetic model can be expressed using equation (9):

$$
\frac{t}{q_{t}}=\frac{1}{k_{2} q_{e}^{2}}+\frac{t}{q_{e}}
$$

where $\mathrm{q}_{\mathrm{e}}\left(\mathrm{mg} \cdot \mathrm{g}^{-1}\right)$ is the amount of adsorbate adsorbed at equilibrium, $\mathrm{q}_{\mathrm{t}}\left(\mathrm{mg} \cdot \mathrm{g}^{-1}\right)$ is the amount of solute adsorbed per unit weight of adsorbent at time, $\mathrm{k}_{2}\left(\mathrm{~min}^{-1}\right)$ is the rate constant of pseudosecond-order sorption. The rate parameters $\mathrm{k}_{2}$ and $\mathrm{q}_{\mathrm{e}}$ can be directly obtained from the intercept and slope of the plot of $\mathrm{t} / \mathrm{q}_{\mathrm{t}}$ versus $\mathrm{t}$.

\section{Result and discussion}

\subsection{Structural, surface and chemical characterization of the adsorbent}

Many sources of graphenic materials are currently commercially available or synthesized by the researchers themselves for their utilization as adsorbent for dye removal. With the aim of providing a comprehensive analysis of the mechanisms involved in the efficiency of adsorption capacity, a deep investigation of the structural, chemical and surface properties of the used graphene nanoplatelets has been conducted. Typical SEM images of rGNP and fGNP1 are shown in figure 1. For both rGNP and fGNP1, the GNPs appear as thin platelets with of a typical size of 1-5 mm (in agreement with supplier's information); they have a clean and smooth surface and crumple edges. SEM observations of fGNP2 and fGNP3 have a similar aspect than that observed for fGNP1 (not shown). 

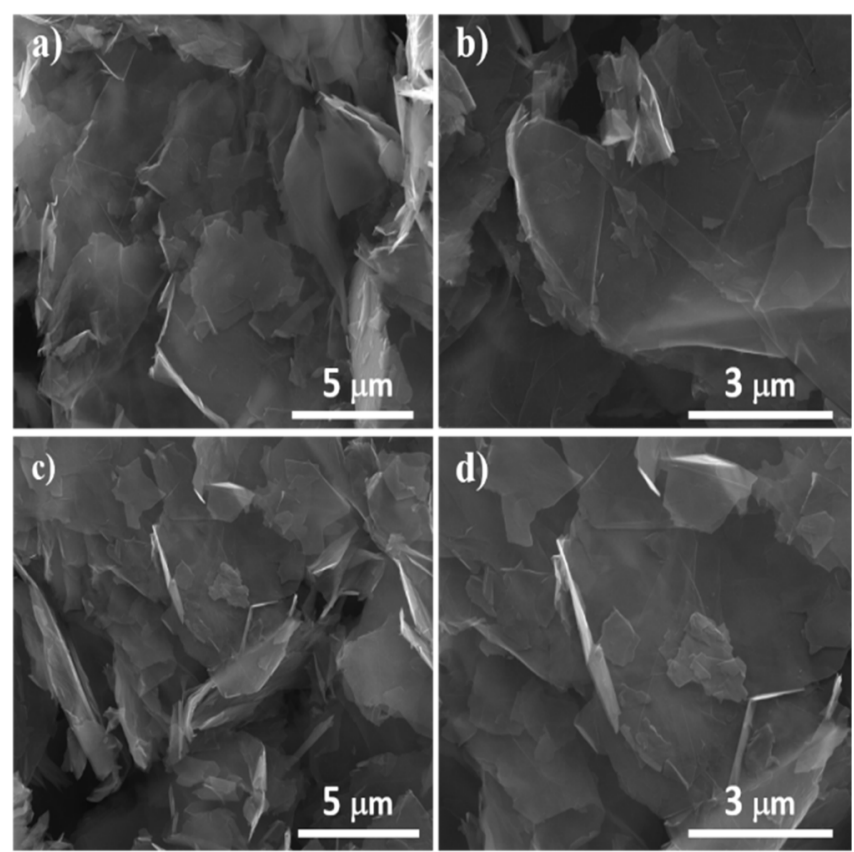

Figure 1 Typical SEM images of (a) and (b) rGNP and (c) and (d) fGNP1 at different magnifications.
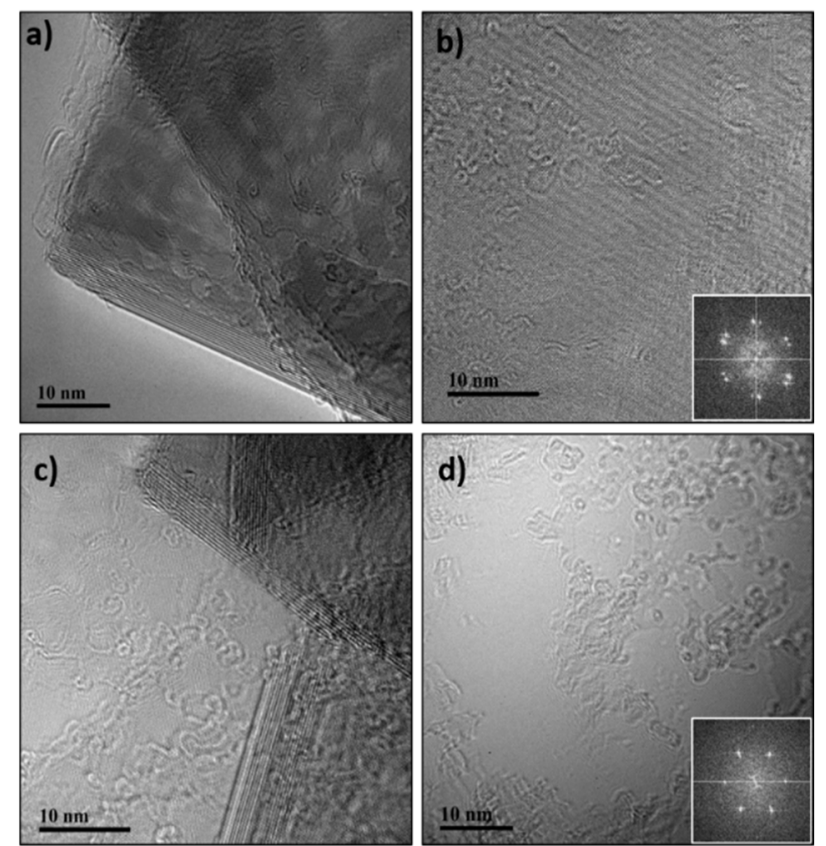

Figure 2 HRTEM micrographs of (a) and (b) rGNP and (c) and (d) fGNP1. FFT is shown for images $b$ and $d$.

From HRTEM images (figure 2), GNP layers (<15 layers) were clearly observed indicating a high graphitization degree and a good structural quality of rGNP. In agreement with SEM 
observations, no significant modification of the morphological characteristics is observed for fGNP1 by HRTEM. Both HRTEM and FFT images put into evidence the good quality of the basal plane of fGNP1 after the applied chemical treatment (figure 2d).

TGA was performed to analyze the thermal stability of the used GNP-based samples in an oxidative (dry air) atmosphere and the thermograms for rGNP and fGNP1 are shown in figure 3. rGNP and fGNP1 show a quite similar general shape with two main weight losses due to combustion: a weight loss of around $20 \%$ of the sample weight in the $400-450^{\circ} \mathrm{C}$ temperature range and a second weight loss of around $80 \%$ of the sample around $650^{\circ} \mathrm{C}$. The remaining mass after combustion of the carbon species above $700^{\circ} \mathrm{C}$ is very low (less than 1 wt.\%) meaning that almost no residues remains in fGNP1 after the applied chemical treatment. This ensures that rGNP and fGNP1 are of good purity and that the prepared adsorbent is an allcarbon nanomaterial. For both samples, combustion occurs thus in two stages. The lower temperature combustion could be due to the presence of carbonaceous species of low structural quality from the GNP synthesis process itself. The main combustion temperature is not modified by the used acid-based treatment.

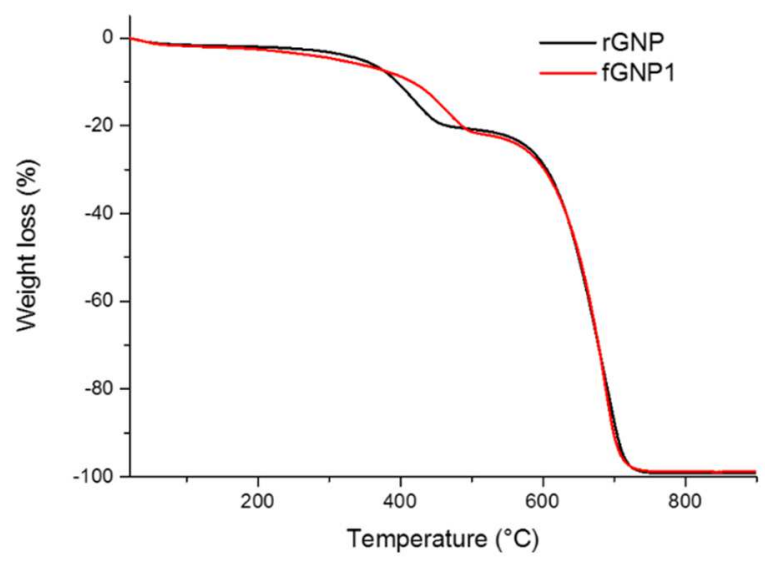

Figure 3 Thermograms under air of rGNP (black) and fGNP1 (red). 
In agreement with the good structural characteristics and the number of layers (10-15 layers) observed by HRTEM, the main combustion temperature of both rGNP and fGNP1 is relatively high. The combustion of poorly ordered carbon species like amorphous carbon usually occurs below $400^{\circ} \mathrm{C}$ while graphite burns off above $700^{\circ} \mathrm{C}$ (Mercier et al. 2013). That means that the chemical method has not induced any strong modification within the layered body of the used GNP.

Commonly used as a complementary technique of HRTEM and TGA, Raman spectroscopy is a commanding method to finely probe structural modification of nanostructured carbon materials through covalent functionalization. The $\mathrm{G}$ band originating from the $\mathrm{sp}^{2}$ bonded carbon atoms of the hexagonal lattice of a graphitic structure is well visible around $1585 \mathrm{~cm}^{-1}$. The intensity of the $\mathrm{D}$ band around $1350 \mathrm{~cm}^{-1}$ is expected to increase when $\mathrm{sp}^{2}$ hybridization of the carbon atoms turns to $\mathrm{sp}^{3}$ due to functional group grafting. Figure 4 shows the Raman spectra of the GNPs before and after the used chemical treatments. In agreement with the good structural quality of the starting rGNP, its D band is relatively sharp and of weak intensity; $\mathrm{I}_{\mathrm{D}} / \mathrm{I}_{\mathrm{G}}$ is of 0.35 for rGNP. After the applied acid-based reaction for all the used conditions, the D band is significantly more pronounced, with a larger and more intense peak. $\mathrm{I}_{\mathrm{D}} / \mathrm{I}_{\mathrm{G}}$ of fGNP1, fGNP2 and fGNP3 are $0.91,0.60$ and 0.55 , respectively. $\mathrm{I}_{\mathrm{D}} / \mathrm{I}_{\mathrm{G}}$ increases of a factor of 1.5 or more compared to that of rGNP depending on the used acid mixture, the highest $\mathrm{I}_{\mathrm{D}} / \mathrm{I}_{\mathrm{G}}$ being observed for fGNP1 treated with the $\mathrm{H}_{2} \mathrm{SO}_{4}: \mathrm{HNO}_{3}$ ratio of $1: 1$. Functionalization probably occurred mainly at the edges and at the basal plane of the external layers of the GNP without any significant attack of the internal layers which leads to an increase of the $\mathrm{I}_{\mathrm{D}} / \mathrm{I}_{\mathrm{G}}$ ratio and the preservation of their graphitic quality (from TGA and HRTEM). 


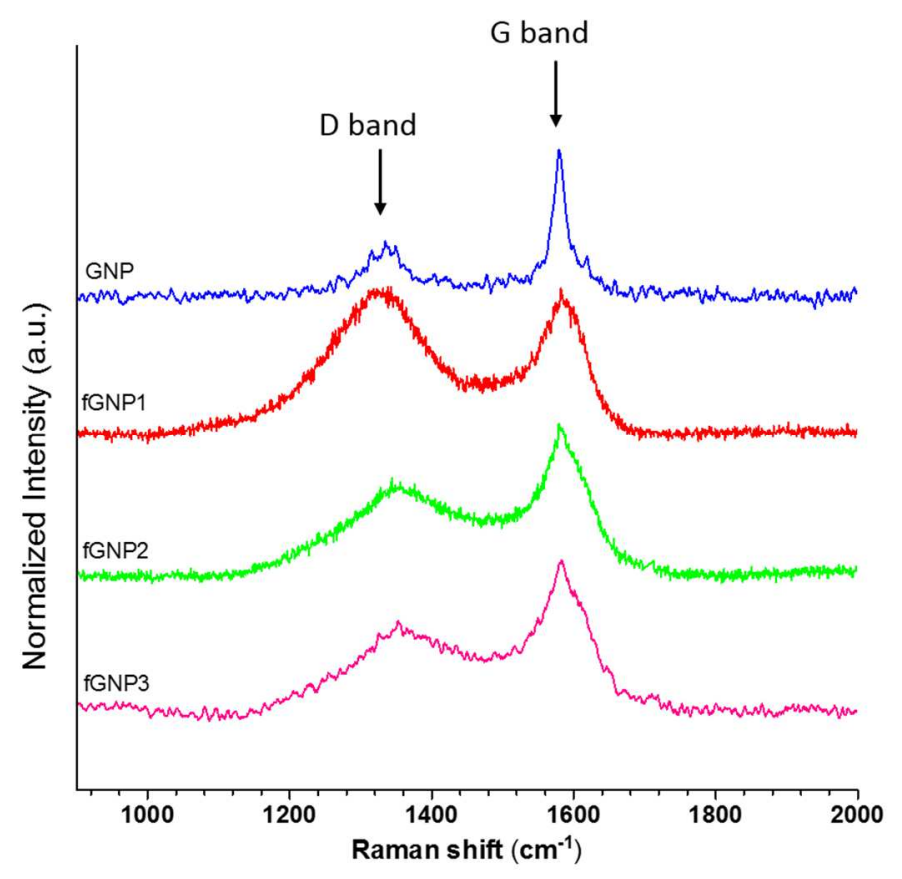

Figure 4 Raman spectra of rGNP, fGNP1, fGNP2 and fGNP3.

Presence of the oxygen containing functional groups expected to be grafted by the proposed chemical method has been investigated by FTIR. The FTIR spectra of rGNP, fGNP1, fGNP2 and fGNP3 are presented in figure 5. 


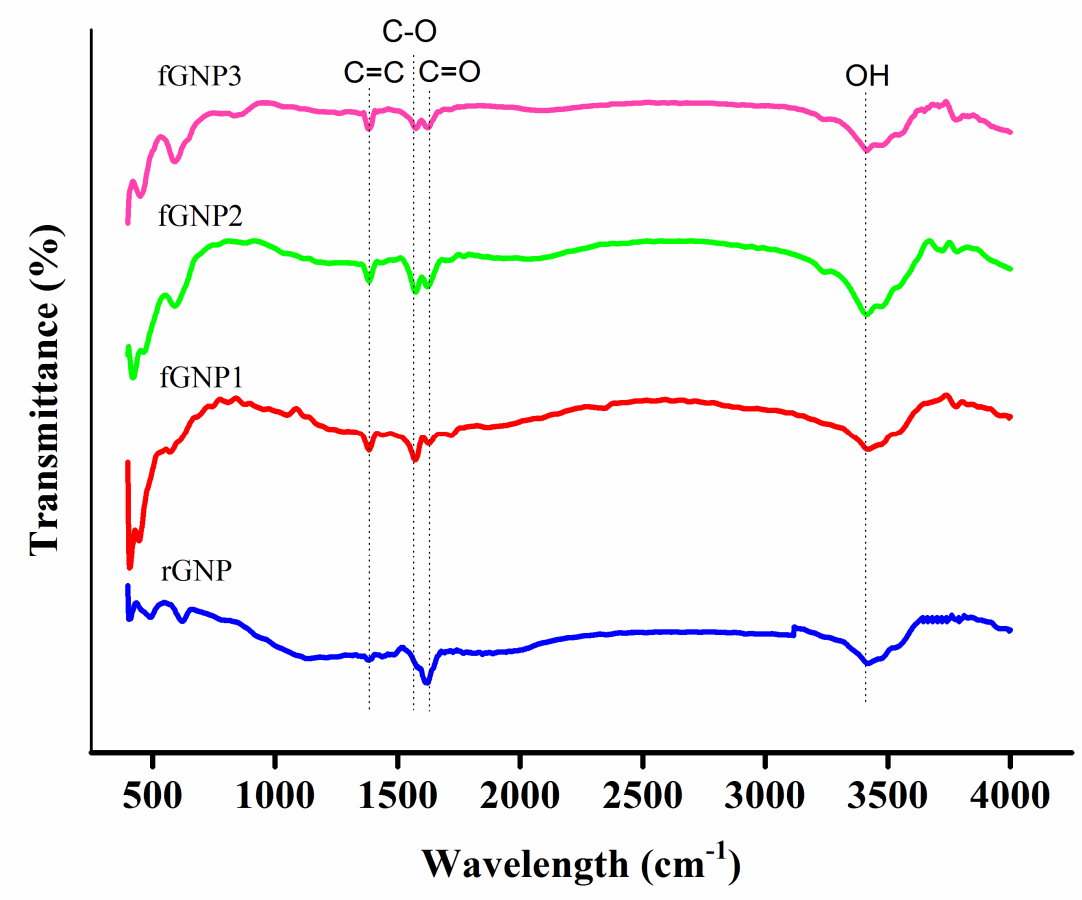

Figure 5 FTIR spectra of rGNP, fGNP1, fGNP2 and fGNP3.

The $\mathrm{C}=\mathrm{C}$ stretching vibrations commonly observed around $1600 \mathrm{~cm}^{-1}$ for graphenic materials were well visible for all the samples. O-H stretching variations is visible for all GNP samples around $3400-3600 \mathrm{~cm}^{-1}$ and after functionalization $\mathrm{C}=\mathrm{O}$ and $\mathrm{C}-\mathrm{O}$ stretching vibrations appear in the $1720 \mathrm{~cm}^{-1}$ and $1570-1600 \mathrm{~cm}^{-1}$ range, respectively (Amiri et al. 2016). Oxygencontaining groups are evidenced in the acid treated GNP by FTIR.

From XPS analysis, O/C atomic ratio between GNP and fGNP1 (being of 3.54 and 4.89, respectively) was found to be increased of $38 \%$ after functionalization. C1s peak of GNP and fGNP1 is shown in figure 6 . The contribution at around $286 \mathrm{eV}$ assigned to carbon covalently linked oxygen (contribution $\mathrm{C} 1 \mathrm{~s} \mathrm{C}-\mathrm{O}$ ) is more pronounced for fGNP1. The area ratio between the $\mathrm{C} 1 \mathrm{~s} \mathrm{sp} \mathrm{sp}^{2}$ contribution and that of the $\mathrm{C} 1 \mathrm{~s} \mathrm{C}-\mathrm{O}$ one for GNP and fGNP1, respectively, is of $28 \%$ meaning that the main part of oxygen introduced in the sample by functionalization belong to oxygen-containing functions grafted to the $\mathrm{sp}^{2}$ network of graphene. 

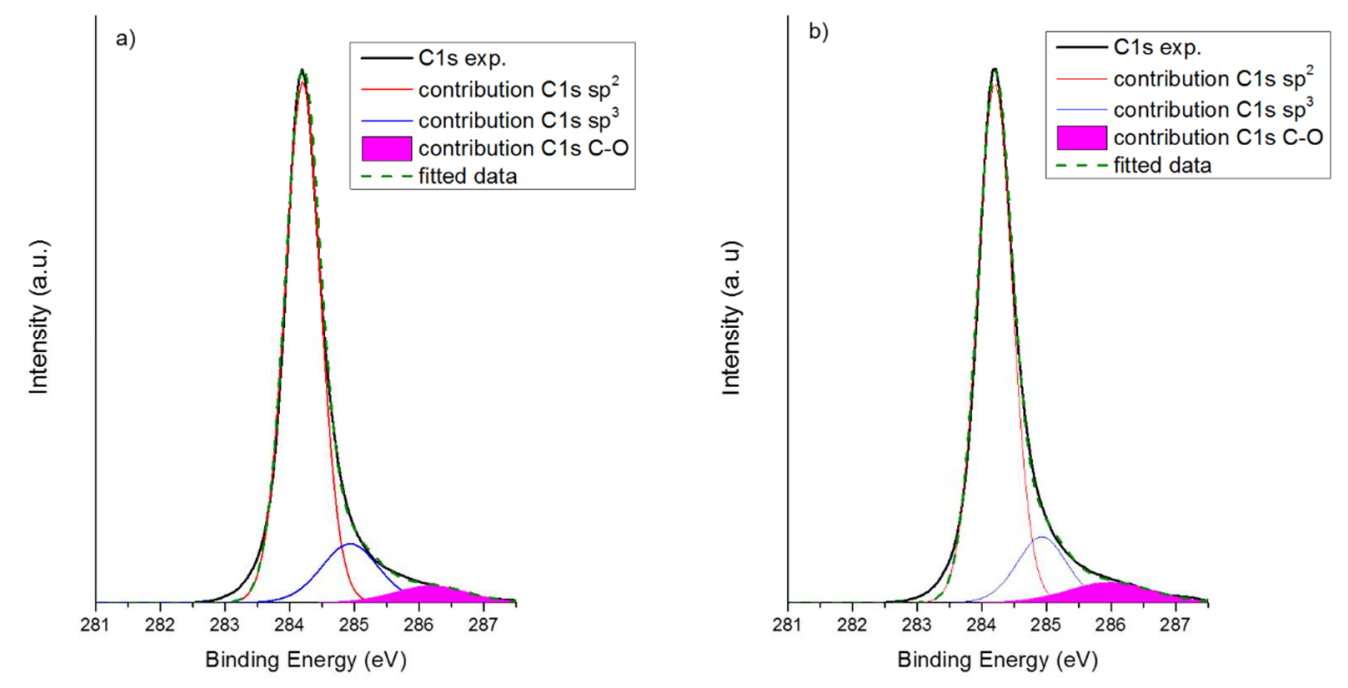

Figure 6 C1s peak from XPS for (a) GNP and (b) fGNP1.

In summary, oxygen-containing groups could be efficiently grafted at the GNP external surface by the used $\mathrm{H}_{2} \mathrm{SO}_{4} / \mathrm{HNO}_{3}$ mixture. Even if carboxylic groups are most often reported for such acid attack of carbon nanomaterials, other kinds of functional groups such as lactone or carbonyl are certainly also present. Their precise nature is difficult to determine. Their hydrophilic character is however expected to play a crucial role for the efficient dispersion of the GNP and their use as MB adsorbent in water. This is the reason why fGNP1 which has shown the highest $I_{D} / I_{G}$ ratio of the fGNP series has been chosen for the following investigations.

\subsection{Improved dispersion in water}

The accessible surface and the porosity properties of the used adsorbents are important factors for adsorption process of dye molecules. A porous morphology and high surface area are considered to provide more active adsorption sites leading to an enhanced adsorption uptake. 
Surface area, pore volume and pore size of rGNP and fGNP1 are gathered in Table 1. In agreement with the supplier's information, for the starting rGNP sample the surface areas (BET and Langmuir) are not higher than 117 and $167 \mathrm{~m}^{2} \cdot \mathrm{g}^{-1}$. As discussed below, these values are much lower than those usually found for other kinds of graphene such as GO for example (see Table 1). GO has usually 2-5 layers with a highly defected structure while the used GNP are composed of thick nanosheets (of 10-15 layers from HRTEM) but they are of far better structural quality. Even if the applied acid-based chemical treatment seems to only impact the external part of the GNP, it induces a significant increase of $20-40 \%$ of all the surface properties. And the micropore volume is increased by a factor of almost 4 for fGNP1.

Table 1 Surface and porosity properties of rGNP and fGNP1.

\begin{tabular}{|c|c|c|c|c|}
\hline Sample & $\begin{array}{c}\text { BET surface } \\
\text { area } \\
\left(\mathrm{m}^{2} \cdot \mathrm{g}^{-1}\right)\end{array}$ & $\begin{array}{c}\text { Micropore surface } \\
\text { area } \\
\left(\mathrm{m}^{2} \cdot \mathrm{g}^{-1}\right)\end{array}$ & $\begin{array}{c}\text { Langmuir surface } \\
\text { area } \\
\left(\mathrm{m}^{2} \cdot \mathrm{g}^{-1}\right)\end{array}$ & $\begin{array}{c}\text { Micropore volume } \\
\left(\mathrm{cm}^{3} \cdot \mathrm{g}^{-1}\right)\end{array}$ \\
\hline rGNP & 117 & 53 & 167 & 0.027 \\
\hline fGNP1 & 140 & 73 & 198 & 0.128 \\
\hline
\end{tabular}

High quality pristine graphene nanosheets are widely known to be highly hydrophobic due to the electron delocalization of the $\mathrm{sp}^{2}$ network of the carbon atoms. Their dispersion in aqueous solvents is strongly compromised without any chemical modification (Hayyan et al. 2015). After having been dispersed in water, while rGNP rapidly precipitated, the dispersion of the functionalized GNPs remained relatively stable with eyes (dark solution). Zeta potential is commonly used to evaluate the colloidal stability of dispersions containing nanoparticles. In agreement with visual observations, the zeta potential of rGNP is as low as $-11 \mathrm{mV}$ (Table 2) meaning that the dispersion attraction forces exceed repulsion leading to poor stability (Mohandoss et al. 2017). After the performed surface functionalization, zeta potential is 
significantly reduced for all the fGNP samples. It is of -44 and $-48 \mathrm{mV}$ for fGNP2 and fGNP3, respectively. For fGNP1, it is reduced to $-59 \mathrm{mV}$. Usually, an absolute value of a zeta potential of $40-60 \mathrm{mV}$ is found for high stable dispersions (Ali et al. 2018). The applied chemical treatments could increase affinity between GNP surface and the MB solution through grafting of oxygenated functional groups inducing a good dispersibility of fGNP.

Table 2 Zeta Potential values for rGNP, fGNP1, fGNP2 and fGNP3 dispersed in water

\begin{tabular}{|c|c|}
\hline Samples & Zeta potential $(\mathrm{mV})$ \\
\hline rGNP & -11 \\
\hline fGNP1 & -59 \\
\hline fGNP2 & -44 \\
\hline fGNP3 & -48 \\
\hline
\end{tabular}

\subsection{Hydrophilicity by water}

Figure 7a shows the contact angle of a water droplet of raw GNP compared to the functionalized GNP (figs. $7 b-7 d$ ). The contact angle of GNP decreased from $\sim 58^{\circ}$ down to $\sim 23^{\circ}$ with the hydrophilic nature of the grafted moieties at the GNP sheet surface for GNP and fGNP1, respectively. The contact angle for fGNP2 and fGNP3 was approximately $\sim 35^{\circ}$ and $\sim 40^{\circ}$, respectively. 
(a)

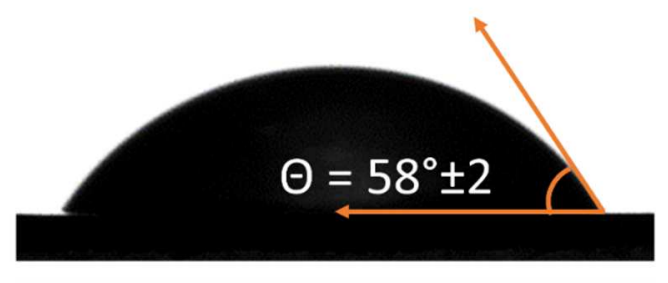

(c) (b)

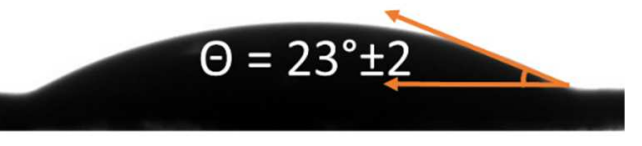

(d)

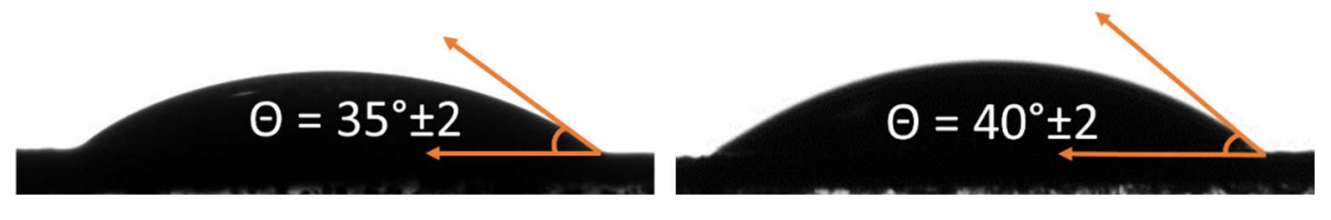

Figure 7 Contact angle measurements of aqueous dispersions of (a) GNP, (b) fGNP1, (c) fGNP2 (d) fGNP3.

\subsection{Effect of adsorption parameters on MB removal}

Among the parameters playing the major role in dye adsorption capacity, initial concentration, contact time, tempearture and $\mathrm{pH}$ are known to be relevant. To follow MB adsorption, UV-vis absorption spectra of the MB solution placed in contact with the raw and the functionalized GNP (rGNP and fGNP1) were recorded after the chosen contact time. Figure 8 shows the evolution of the absorbed intensity in the visible spectral domain of the MB solutions with increasing the contact time with the adsorbent. 

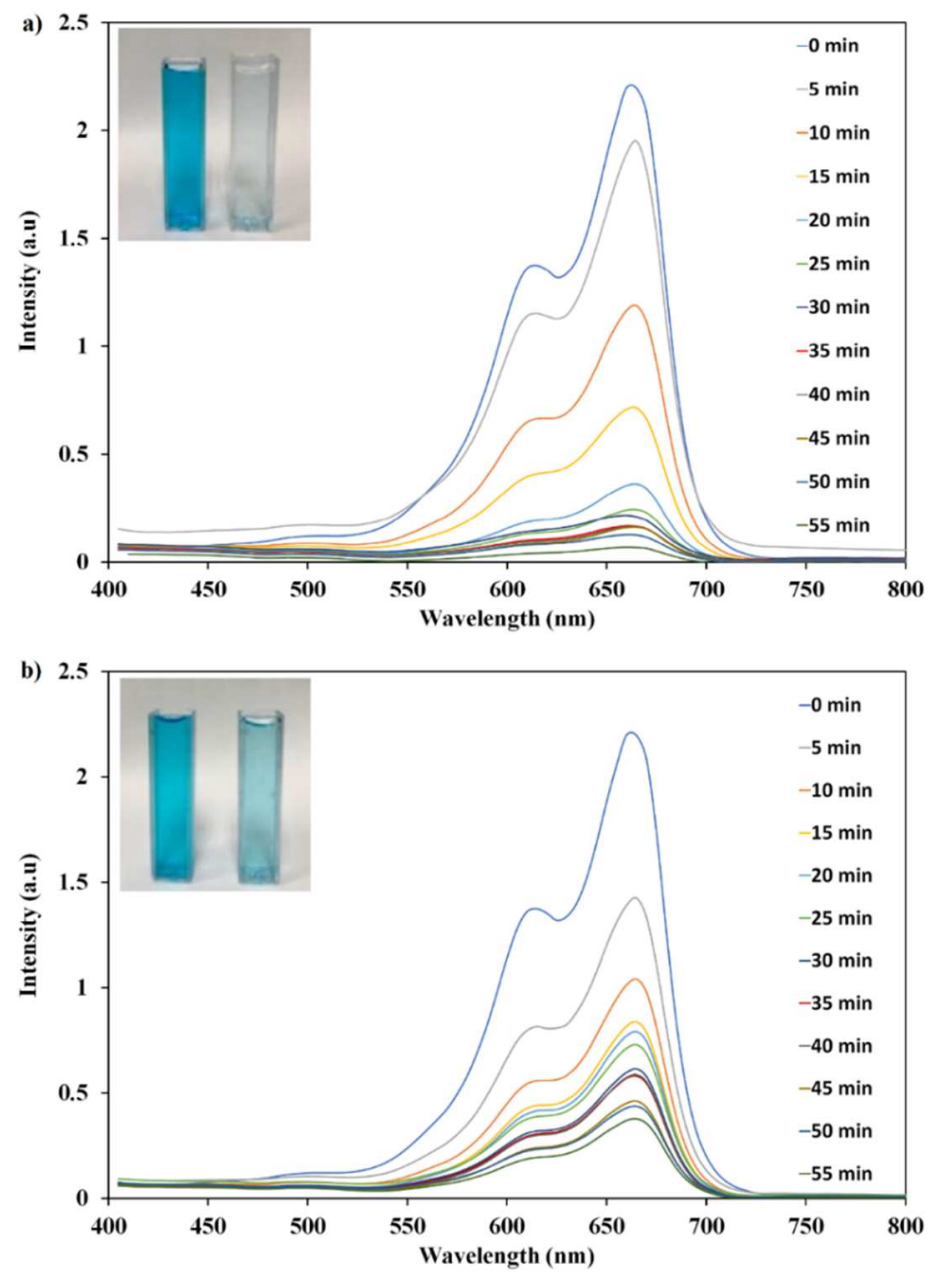

Figure 8 UV-vis absorption spectra after various contact times of MB (a) with fGNP1 and (b) rGNP. Insert: aspect of the MB solution in the UV-visible cell after a contact time $t=0$ (left) and t=55 min (right) with (a) fGNP1 and with (b) rGNP1, respectively.

After a contact time of $55 \mathrm{~min}$, the disappearance of the blue color of MB by fGNP1 is obvious leading to an almost colorless solution contrary to with rGNP used as adsorbent. For all the samples, the absorption spectra show a similar shape with two broad peaks at around 605 and $665 \mathrm{~nm}$. The evolution of the intensity of the absorbed intensity as a function of the contact time is analyzed in the following section by using the most intense peak (at $665 \mathrm{~nm}$ ) to determine the MB removal rate. 


\subsubsection{Effect of MB initial concentration and contact time on adsorption equilibrium}

Batch adsorption of $\mathrm{MB}$ from aqueous solution was carried out, while the initial dye concentration was varied in the range of (25-200) mg.L $\mathrm{L}^{-1}$. Figure 9 shows the effects of MB initial concentration and contact time against the MB removal for both rGNP and fGNP1 at 60 ${ }^{\circ} \mathrm{C}$. As normally observed, MB removal increases as a function of contact time for rGNP and fGNP1. For all the conditions and both adsorbents, the adsorption process is of greatest rate at the beginning, i.e. for short contact times. As the contact time increases, MB adsorption rate slows down much more rapidly for rGNP than for fGNP1 which shows a continuous increase of the MB adsorption until 45 min of contact time for all the used initial concentrations. At the preliminary stage of adsorption, the accessibility of vacant surface sites is favored and after a certain time period, the number of occupied sites increases and repulsive forces certainly appear between the adsorbed $\mathrm{MB}$ and the $\mathrm{MB}$ remaining in the bulk phase (Banerjee and Chattopadhyaya 2017). The equilibrium time is reached at around $45 \mathrm{~min}$ for both adsorbents and all the used conditions. Depending on the MB initial concentration, the maximum of adsorption efficiency is in the 53-65 \% and 76-88 \% range for rGNP and fGNP1, respectively. 

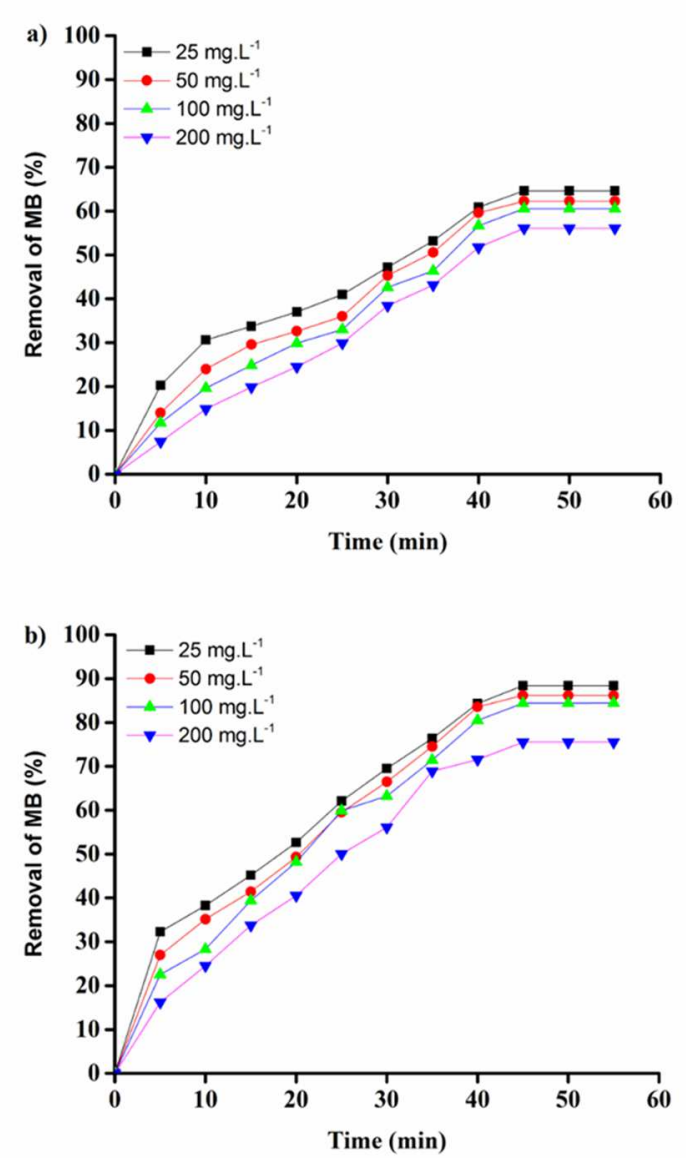

Figure 9 Variation of MB removal with respect to time of (a) rGNP and (b) fGNP1 at $\mathrm{pH}=4$ and $\mathrm{T}=60{ }^{\circ} \mathrm{C}$.

However, increasing in dye concentration leads to a continuous decrease in adsorption for both rGNP and fGNP1, as normally observed. fGNP1 shows significantly higher adsorbent properties with a maximum of MB removal of $87 \%$ compared to $65 \%$ for rGNP at $25 \mathrm{mg} . \mathrm{L}^{-1}$ of initial concentration of MB. An improvement of more than $27 \%$ is therefore achieved after GNP functionalization. The functionalization reaction has certainly several effects that are possibly combined to reach the high removal MB efficiency obtained for our adsorbent. Even if it is limited, the functionalization process could induce structural damaging increasing the intrinsic surface area of fGNP1 compared to rGNP. The grafted oxygen-containing functional groups are responsible for the observed better dispersion of the modified GNP which offer as 
well higher accessible surface for dye adsorption. The GNP being more hydrophilic, they have a better affinity with MB. The maximum MB removal efficiency by fGNP1 is consequently as high as $87 \%$ leading to a highly efficient adsorbent.

\subsubsection{Effect of solution pH on MB adsorption}

$\mathrm{pH}$ is a key factor for adsorption processes especially for carboxylated carbon nanomaterials since their surface properties highly depend on the $\mathrm{pH}$ in the surrounding water. The resulted interactions between $\mathrm{MB}$, having both charged and hydrophobic parts, are expected to be modified through $\mathrm{pH}$ modification. Figure 10 shows the effect of solution $\mathrm{pH}$ on the $\mathrm{MB}$ removal by fGNP1. The highest MB adsorption by fGNP1 was achieved at $\mathrm{pH} 4$, with $\mathrm{MB}$ removal as high as $88.42 \%$, at MB initial concentration of $100 \mathrm{mg} . \mathrm{L}^{-1}$. In aqueous medium, MB shows a $\mathrm{pKa}$ of 5.8 indicating that it can exist in the molecular form when the $\mathrm{pH}<\mathrm{pKa}$ and ionized form when the $\mathrm{pH}>\mathrm{pKa}$ (Zazouli et al. 2016). Carboxylic acid groups at the GNP surface are negatively charged above $\mathrm{pH}$ 4-5 (COOH pKa), meaning that at low $\mathrm{pH}$, for which MB adsorption is high, GNP surface is probably not charged. Moreover, contrary to GO, the functionalization level is here rather low since it could be estimated from Temperatureprogrammed desorption (TPD) to be around 1 functional groups every $6 \mathrm{C}_{6}$-ring of GNP in average (cf. Supporting Information, Fig. S1). Even if we consider that the used GNPs are rather thick and that the functional groups are mainly situated at the external surface of the nanoplatelets (more reactive sites), it is likely to find hydrophobic zones under the form of $\mathrm{sp}^{2}$ non-oxidized domains on the basal plane of the functionalized GNPs. Since the MB molecule has two aromatic rings with $\pi$ electrons, MB-fGNP interactions can be here mostly governed by $\pi-\pi$ stacking; hydrophobic intercations being thus the primary driving force for adsorption in the low pH domain (Li et al. 2013a; Lv et al. 2018; Qi et al. 2018; He et al. 2018). Electrostatic interactions probably become predominant in $\mathrm{MB}$ adsorption at higher $\mathrm{pH}$ when $\mathrm{COOH}$ are 
deprotonated. These negatively charged sites on fGNP basal plane could lead to attractive forces (even if they seem of less intensity than hydrophobic forces) with the positively charged MB especially above pH 5.8 corresponding to MB pKa (Kaya et al. 2018). These two effects contribute to the rather good MB adsorption on fGNP1 surface over a wide $\mathrm{pH}$ range.

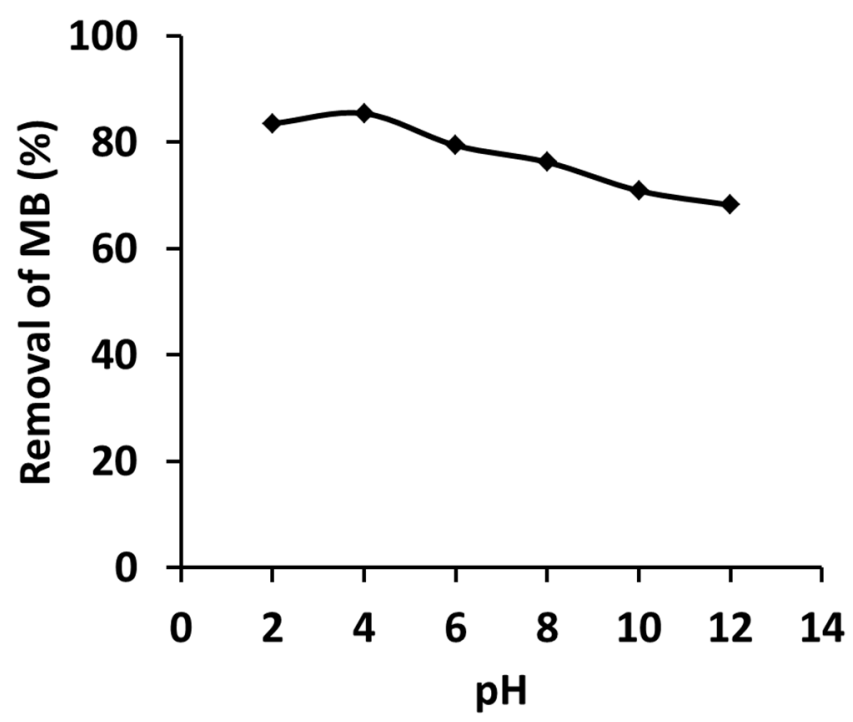

Figure 10 Effect of $\mathrm{pH}$ on $\mathrm{MB}$ removal efficiency at $\mathrm{C}_{0}=200 \mathrm{mg} \cdot \mathrm{L}^{-1}$ and $\mathrm{T}=60{ }^{\circ} \mathrm{C}$.

\subsubsection{Effect of solution temperature on MB adsorption}

Temperature usually has a significant effect on the adsorption process, as any temperature change may affect the adsorption equilibrium (Kushwaha et al. 2017). When the adsorption capacity increases with an increase in temperature, it indicates that the adsorption process is endothermic (Pathania et al. 2017). For this study, three different temperatures (30, 45 and $60^{\circ} \mathrm{C}$ ) were chosen to investigate their effect on MB adsorption. Figure 11 shows the effect of solution temperature on rGNP and fGNP1 adsorption capacity. 

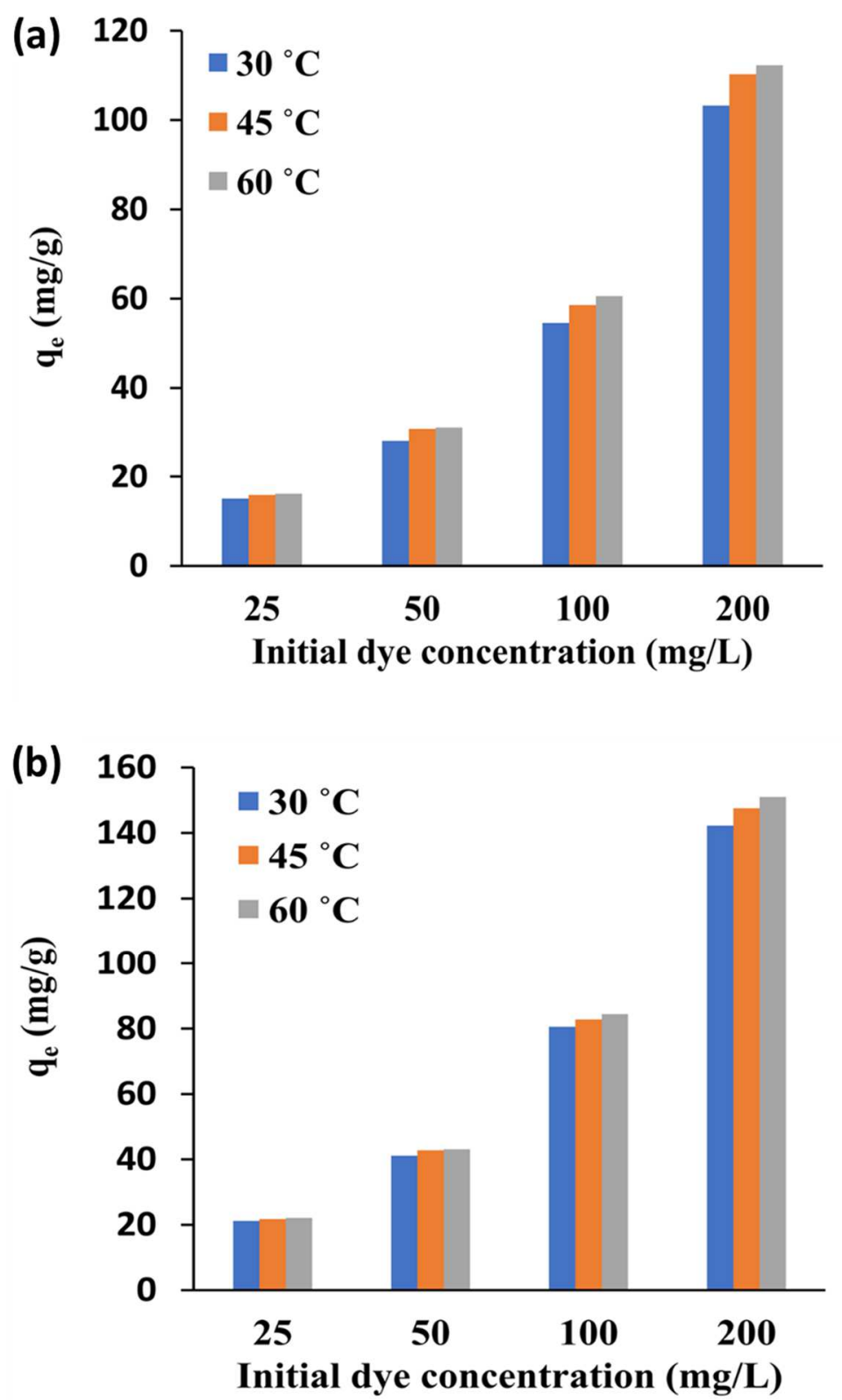

Figure 11 Effect of temperature on the adsorption capacity of (a) rGNP and (b) fGNP1 at $\mathrm{C}_{0}=$ $200 \mathrm{mg} \cdot \mathrm{L}^{-1}$ and $\mathrm{pH} 4$

Based on the results obtained, for rGNP, when the temperature rises from 30 to $60{ }^{\circ} \mathrm{C}$, the amount of adsorbed MB is increased from 15 to $130 \mathrm{mg} \cdot \mathrm{g}^{-1}$, from 16 to $110 \mathrm{mg} \cdot \mathrm{g}^{-1}$ and from 16 to $112 \mathrm{mg} \cdot \mathrm{g}^{-1}$ at 30,45 and $60^{\circ} \mathrm{C}$, respectivly. For fGNP1, when the temperature increases from 
30 to $60{ }^{\circ} \mathrm{C}$, the amount of adsorbed MB is incaresed from 21 to $142 \mathrm{mg} \cdot \mathrm{g}^{-1}$, from 22 to 147 mg. $\mathrm{g}^{-1}$ and from 22 to $151 \mathrm{mg} \cdot \mathrm{g}^{-1}$ at 30,45 and $60{ }^{\circ} \mathrm{C}$, respectively. The MB adsorption by both rGNP and fGNP1 is thus an endothermic process. When temperature increases, dye mobility increases enhancing that way its interaction with the active sites of the adsorbent surface (Banerjee and Chattopadhyaya 2017).

\subsection{Adsorption isotherm study of MB adsorption on the chemically modified graphene}

\section{nanoplatelets}

In this study, the linear forms of the isotherm models of Langmuir, Freundlich and Temkin were investigated at 30,45 and $60{ }^{\circ} \mathrm{C}$. Figure 12 shows the determined separation factor $\mathrm{R}_{\mathrm{L}}$ versus the initial concentration of MB for its adsorption on fGNP1. The $\mathrm{R}_{\mathrm{L}}$ values are in the 0 1 range confirming that the adsorption of MB on the modified GNPs is favorable for the used concentration ranges, i.e. $25,50,100$ and $200 \mathrm{mg} \cdot \mathrm{L}^{-1}$.

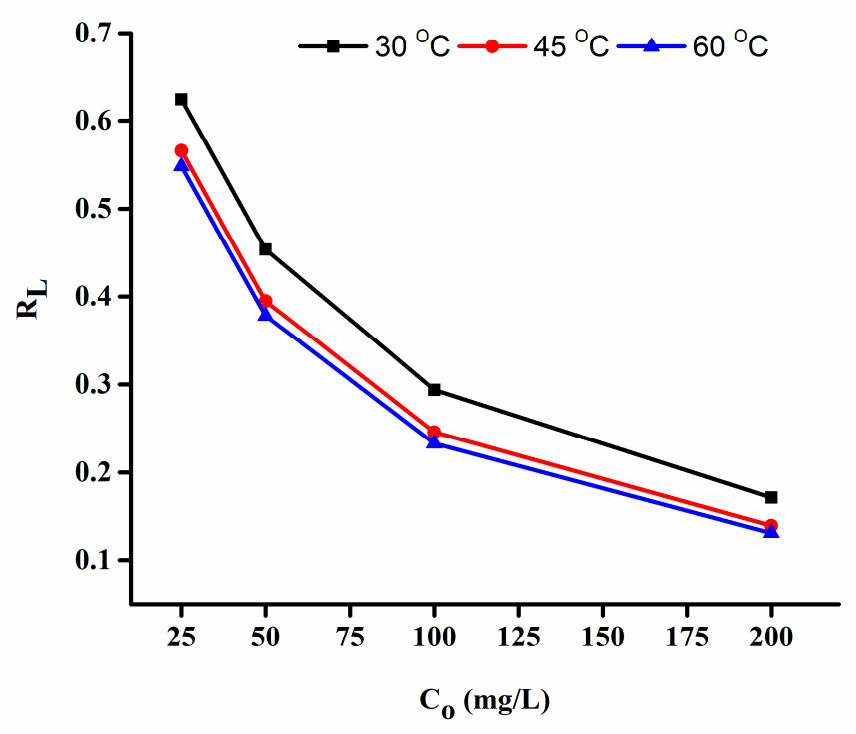

Figure 12 Separation factor $\left(\mathrm{R}_{\mathrm{L}}\right)$ as a function of the initial concentration of $\mathrm{MB}$ for its adsorption on fGNP1 at 30,45 and $60^{\circ} \mathrm{C}$. 
Table 3 summarizes all the three isotherm model constants and correlation coefficients for MB adsorption onto fGNP1 adsorbent. For all the temperatures, $\mathrm{R}^{2}$ being higher for Langmuir than for Freundlich and Temkin models (Langmuir > Freundlich > Temkin), Langmuir adsorption better describes MB adsorption isotherms. MB monolayer coverage mainly occurs on the outer surface of the functionalized GNPs. In addition, this result also compliments to the error function analysis where the calculated value of $\chi^{2}$ gained is between 0.030 and 0.045 , which is the lowest among the three isotherm models. Freundlich $1 / \mathrm{n}$ constant is found to be above 1 indicating also a favorable adsorption for our MB/GNP1 system. Moreover, in agreement with MB adsorption evolution with temperature (Fig. 10), the adsorption reaction is endothermic since B value from Temkin analysis is positive.

Table 3 Langmuir, Freundlich and Temkin isotherm model constants and correlation coefficients.

\begin{tabular}{|c|c|c|c|c|c|c|}
\hline \multirow[b]{2}{*}{ Isotherms } & \multirow{2}{*}{$\begin{array}{c}\text { Solution } \\
\text { temperature } \\
\left({ }^{\circ} \mathrm{C}\right)\end{array}$} & \multicolumn{4}{|c|}{ Constants } & \multirow[b]{2}{*}{$\mathrm{R}^{2}$} \\
\hline & & $\begin{array}{c}\mathrm{Q}_{\mathrm{m}} \\
\left(\mathrm{mg} \cdot \mathrm{g}^{-1}\right)\end{array}$ & $\begin{array}{c}\mathrm{K}_{\mathrm{L}} \\
\left(\mathrm{L} . \mathrm{mg}^{-1}\right)\end{array}$ & $\mathrm{R}_{\mathrm{L}}$ & $\chi^{2}$ & \\
\hline \multirow{4}{*}{ Langmuir } & 30 & 245.5 & 0.024 & 0.62 & 0.0453 & 0.9943 \\
\hline & 45 & 239.0 & 0.030 & 0.57 & 0.0039 & 0.9996 \\
\hline & 60 & 244.0 & 0.033 & 0.55 & 0.0431 & 0.9955 \\
\hline & & \multicolumn{4}{|c|}{ Constants } & \\
\hline Isotherms & $\begin{array}{c}\text { Solution } \\
\text { temperature } \\
\left({ }^{\circ} \mathrm{C}\right)\end{array}$ & $\begin{array}{c}K_{\mathrm{F}} \\
\left(\mathrm{mg} \cdot \mathrm{g}^{-1}\left(\mathrm{~L} \cdot \mathrm{mg}^{-1}\right)^{1 / n}\right)\end{array}$ & $1 / \mathrm{n}$ & - & $\chi^{2}$ & $\mathrm{R}^{2}$ \\
\hline \multirow{3}{*}{ Freundlich } & 30 & 8.60 & 1.40 & - & 0.5604 & 0.9875 \\
\hline & 45 & 10.5 & 1.46 & - & 0.5294 & 0.9874 \\
\hline & 60 & 11.3 & 1.46 & - & 0.5902 & 0.9155 \\
\hline
\end{tabular}




\begin{tabular}{|c|c|c|c|c|c|c|}
\hline \multirow{2}{*}{ Isotherms } & \multirow{2}{*}{$\begin{array}{c}\text { Solution } \\
\text { temperature } \\
\left({ }^{\circ} \mathrm{C}\right)\end{array}$} & \multicolumn{4}{|c|}{ Constants } & \multirow[b]{2}{*}{$\mathrm{R}^{2}$} \\
\hline & & $\begin{array}{c}\mathrm{A}_{\mathrm{T}} \\
\left(\mathrm{L} \cdot \mathrm{mg}^{-1}\right)\end{array}$ & B & - & $\chi^{2}$ & \\
\hline \multirow{3}{*}{ Temkin } & 30 & 0.34 & 45.50 & - & 18.3941 & 0.8777 \\
\hline & 45 & 0.34 & 45.50 & - & 19.2134 & 0.9104 \\
\hline & 60 & 0.45 & 46.55 & - & 19.9450 & 0.9155 \\
\hline
\end{tabular}

\subsection{Kinetic analysis of MB adsorption on the chemically modified graphene nanoplatelets}

Adsorption kinetic study is important for water treatment since it provides valuable information on reaction pathways and the adsorption mechanisms. It determines how the adsorption rates depends on the initial concentration of the adsorbate in solution and how the rates are affected by the adsorption capacity or the adsorbent characteristics.

Tables 4 lists the results of the rate constants from analysis by the pseudo first order and pseudo second order model for different initial MB concentrations at temperature 30, 45, and $60{ }^{\circ} \mathrm{C}$. MB adsorption on the carboxylated GNPs is then better represented by the pseudo-firstorder kinetic model since the calculated $\mathrm{q}_{\mathrm{e}}$ value is found to be closer to the experimental $\mathrm{q}_{\mathrm{e}}$ in agreement with the high correlation number found $\left(\mathrm{R}^{2}\right.$ of around 0.98$)$. This study indicates that the MB-fGNP1 adsoprtion is more inclined towards physisorption, as expected.

Table 4 Kinetic parameters and coefficients for the pseudo-first-order and pseudo-second-order model applied to MB adsorption on the functionalized GNP surface.

\begin{tabular}{|c|c|c|c|c|c|c|}
\hline \multirow{3}{*}{$\begin{array}{c}\text { Temperature } \\
\left({ }^{\circ} \mathrm{C}\right)\end{array}$} & \multirow{3}{*}{ Kinetic Model } & Kinetic & \multicolumn{3}{|c|}{ Initial dye concentration (mg/L) } \\
\cline { 5 - 7 } & & parameter & 25 & 50 & 100 & 200 \\
\cline { 5 - 7 } & & $\mathrm{q}_{\mathrm{e} e x p}(\mathrm{mg} / \mathrm{g})$ & 21.1666 & 41.1342 & 80.5659 & 142.2466 \\
\hline 30 & & $\mathrm{q}_{\mathrm{ecal}}$ & 20.5315 & 40.1082 & 78.1925 & 140.9537 \\
\hline
\end{tabular}




\begin{tabular}{|c|c|c|c|c|c|c|}
\hline & \multirow{2}{*}{$\begin{array}{l}\text { Pseudo-first } \\
\text { order }\end{array}$} & $\mathrm{k}_{1}$ & 2.9402 & 3.0791 & 2.9570 & 2.6095 \\
\hline & & $\mathrm{R}^{2}$ & 0.9797 & 0.9758 & 0.9790 & 0.9739 \\
\hline & \multirow{3}{*}{$\begin{array}{l}\text { Pseudo-second } \\
\text { order }\end{array}$} & $\mathrm{q}_{\mathrm{e} \mathrm{cal}}$ & 15.1411 & 37.3081 & 70.1280 & 126.3690 \\
\hline & & $\mathrm{k}_{2}$ & 0.0384 & 0.0157 & 0.0043 & 0.0013 \\
\hline & & $\mathrm{R}^{2}$ & 0.8726 & 0.8979 & 0.7642 & 0.5612 \\
\hline & \multirow{3}{*}{ order } & $\mathrm{q}_{\mathrm{e} \mathrm{cal}}$ & 19.5315 & 40.1082 & 81.1925 & 143.9537 \\
\hline & & $\mathrm{k}_{1}$ & 3.2022 & 3.0229 & 2.8384 & 3.4852 \\
\hline & & $\mathrm{R}^{2}$ & 0.9163 & 0.9264 & 0.9781 & 0.8767 \\
\hline & \multirow{3}{*}{$\begin{array}{l}\text { Pseudo-second } \\
\text { order }\end{array}$} & $\mathrm{q}_{\mathrm{e} \mathrm{cal}}$ & 17.5633 & 38.4097 & 78.7495 & 130.6191 \\
\hline & & $\mathrm{k}_{2}$ & 0.0675 & 0.0277 & 0.0085 & 0.0026 \\
\hline & & $\mathrm{R}^{2}$ & 0.8891 & 0.8631 & 0.9359 & 0.6822 \\
\hline \multirow{6}{*}{60} & \multirow{3}{*}{$\begin{array}{l}\text { Pseudo-first } \\
\text { order }\end{array}$} & $\mathrm{q}_{\mathrm{ecal}}$ & 19.0929 & 40.6385 & 82.3589 & 146.6760 \\
\hline & & $\mathrm{k}_{1}$ & 3.0246 & 3.1292 & 3.1007 & 3.8599 \\
\hline & & $\mathrm{R}^{2}$ & 0.9484 & 0.9433 & 0.9677 & 0.8634 \\
\hline & \multirow{3}{*}{$\begin{array}{l}\text { Pseudo-second } \\
\text { order }\end{array}$} & $\mathrm{q}_{\mathrm{e} \mathrm{cal}}$ & 17.6706 & 37.8400 & 76.3371 & 130.6016 \\
\hline & & $\mathrm{k}_{2}$ & 2.5943 & 1.0850 & 0.2666 & 0.0972 \\
\hline & & $\mathrm{R}^{2}$ & 0.7939 & 0.7518 & 0.7031 & 0.6291 \\
\hline
\end{tabular}

\subsection{MB-fGNP interaction forces and adsorption capacity}

Parametric, thermodynamic and kinetic investigations have shown that adsorption of MB on the chemically modified GNPs is remarkably favorable. To develop interesting materials for pollutant removal, the adsorption capacity is one of the major parameters to assess the removal efficiency. As mentioned, a lot of adsorbent-adsorbate systems can be found in literature. They can be very different in nature and their adsorption capacity are difficult to compare. Among the reported results, $\mathrm{MB}$ is often used as a standard to study development of decontaminating 
systems of water. Table 5 gathers findings reported for nanocarbon-based adsorbents developed for MB removal and for which adsorption isotherms can be well fitted with the Langmuir model.

Table 5 Adsorption capacity ( $\mathrm{q}_{\mathrm{m}}$ calculated from Langmuir model) of MB adsorbed by various nanomaterials and the used parameters, SSA and $\mathrm{q}_{\mathrm{m}} / \mathrm{SSA}$

\begin{tabular}{|c|c|c|c|c|c|c|c|c|}
\hline \multirow[b]{2}{*}{$\begin{array}{l}\text { Adsor- } \\
\text { bent }\end{array}$} & \multicolumn{5}{|c|}{ Experimental conditions } & \multirow{2}{*}{$\begin{array}{l}\text { SSA } \\
\left(\mathrm{m}^{2} .\right. \\
\left.\mathrm{g}^{-1}\right)\end{array}$} & \multirow{2}{*}{$\begin{array}{c}\mathrm{q}_{\mathrm{m}} / \mathrm{SS} \\
\mathrm{A} \\
\text { (mg of } \\
\text { MB.c } \\
\mathrm{m}^{-2} \text { ) }\end{array}$} & \multirow[b]{2}{*}{ Ref. } \\
\hline & $\begin{array}{l}\text { Concentrati } \\
\text { on }\left(\mathrm{mg} \cdot \mathrm{L}^{-1}\right)\end{array}$ & $\begin{array}{c}\text { Temperatu } \\
\text { re }\left({ }^{\circ} \mathrm{C}\right)\end{array}$ & $\begin{array}{c}\text { Tim } \\
\text { e } \\
(\min \\
)\end{array}$ & $\mathrm{pH}$ & $\begin{array}{c}\mathrm{qm} \\
\left(\mathrm{mg} \cdot \mathrm{g}^{-}\right. \\
1)\end{array}$ & & & \\
\hline $\begin{array}{c}\mathrm{MWCN} \\
\mathrm{T}\end{array}$ & $20-60$ & 50 & 60 & 10 & 95.2 & 119 & 0.8 & $\begin{array}{l}\text { (Selen et } \\
\text { al. 2016) }\end{array}$ \\
\hline $\begin{array}{c}\text { MWCN } \\
\mathrm{T}\end{array}$ & $15-50$ & 60 & $\begin{array}{l}\text { any } \\
\text { time }\end{array}$ & 7 & 64.7 & N.A. & - & $\begin{array}{l}\text { (Yao et } \\
\text { al. 2010) }\end{array}$ \\
\hline $\begin{array}{c}\text { MWCN } \\
\mathrm{T}\end{array}$ & $5-300$ & 22 & 480 & $\begin{array}{l}6.9- \\
7.9\end{array}$ & 400 & 358 & 1.1 & $\begin{array}{c}\text { (Szlachta } \\
\text { and } \\
\text { Wójtowi } \\
\text { cz 2013) }\end{array}$ \\
\hline $\begin{array}{c}\mathrm{MWCN} \\
\mathrm{T}\end{array}$ & $8-25$ & 50 & 180 & $\begin{array}{l}6.4- \\
9.4\end{array}$ & N.A. & N.A. & - & $\begin{array}{l}\text { (Zhao et } \\
\text { al. 2013) }\end{array}$ \\
\hline GO & $20-70$ & 25 & 500 & 5.4 & 181.81 & N.A. & - & $\begin{array}{c}\text { (Li et al. } \\
\text { 2013b) }\end{array}$ \\
\hline GO & 45 & 60 & 600 & $9-10$ & 306.5 & N.A. & - & $\begin{array}{c}\text { (Guo et } \\
\text { al. 2016) }\end{array}$ \\
\hline rGO & $10-50$ & 10 & 180 & 7 & 339 & 270 & 1.3 & $\begin{array}{l}\text { (Chen et } \\
\text { al. 2013) }\end{array}$ \\
\hline rGO & $20-100$ & 60 & 1300 & 10 & 204.08 & 296 & 0.7 & $\begin{array}{c}\text { (Liu et al. } \\
\text { 2012) }\end{array}$ \\
\hline fGNP1 & $25-200$ & 60 & 55 & 4 & 224.62 & 140 & 1.6 & this work \\
\hline
\end{tabular}


The maximum adsorption capacity $\left(\mathrm{q}_{\mathrm{m}}\right)$ of our modified GNP is rather good but it is lower than most of the GO or rGO reported. As already discussed, our fGNP1 is composed of relatively thick platelets compared to $\mathrm{GO}$ or $\mathrm{rGO}$, for example and its SSA can be quite low compared to that reported for MWCNTs, GO and rGO depending on the sample source. The adsorption process is mainly governed by interactions between the adsorbate and the surface of the adsorbent. This is the reason why it is interesting to compare the adsorption capacity related to the SSA of the adsorbent. This value can be simply calculated by dividing the adsorption capacity $\left(\mathrm{q}_{\mathrm{m}}\right)$ by the corresponding SSA for each carbon nanomaterial (Table 5). $\mathrm{q}_{\mathrm{m}} / \mathrm{SSA}$ corresponds therefore to the amount of $\mathrm{MB}$ adsorbed per $\mathrm{cm}^{2}$ of the used nanomaterials. $\mathrm{MB}$ removal efficiency per surface unit for our modified GNP is significantly higher meaning that the involved interactions between MB and the functionalized GNP are strongly favorable leading to an effective adsorption, in agreement with the thermodynamic and kinetic studies. From the literature, there is no agreement regarding which type of interaction (electrostatic, $\pi$ $\pi$ stacking, van der Waals, hydrophobic, hydrogen bonding) is favorable for each kind of adsorbent. GO for example bears a lot of functional groups such as carboxylic acids that can easily release protons in water leading to an adsorbent surface charged (Dimiev et al. 2012). In that case, adsorption is likely to be governed by electrostatic interactions. For the prepared modified GNPs, we have shown that at low $\mathrm{pH}$, hydrophobic forces could be rather involved in the adsorption process ( $\mathrm{Hu}$ et al. 2013). Hydrophobic interactions are shown here to play a significant role in the observed favorable interactions between MB and fGNP1.

Based on the possible functional groups present at the surface of fGNP1, MB adsorption could follow three mechanisms depending on the adsorption site (Figure 13) (Pérez-Ramírez et al. 2016). First, interaction between the carboxyl groups of fGNP1 and MB could be electrostatic (Figure 13 (a)). The positively charged MB molecules could strongly react on the surface of fGNP1 with the negative charge of the dissociated form of carboxyl groups (Nassar 
et al. 2015; Yusuf et al. 2015). Second, adsorption by hydrogen bonding could occur between the hydrogen or oxygen of the possible epoxide, carboxyl, hydroxyl, carbonyl, etc... groups introduced at fGNP1 surface and oxygen/nitrogen or hydrogen of the MB molecule, respectively (Figure $13(\mathrm{~b})$ ). Thirdly, $\pi-\pi$ interactions are possible between the preserved parts of the GNP surface and the aromatic ring of the dye molecules (Figure 13 (c)). Adsorption was here also probably enhanced by the combination of synergetic effects of all adsorption mechanisms leading to high efficiency of MB dye removal by the chemically functionalized GNP (Lan Huong et al. 2018).

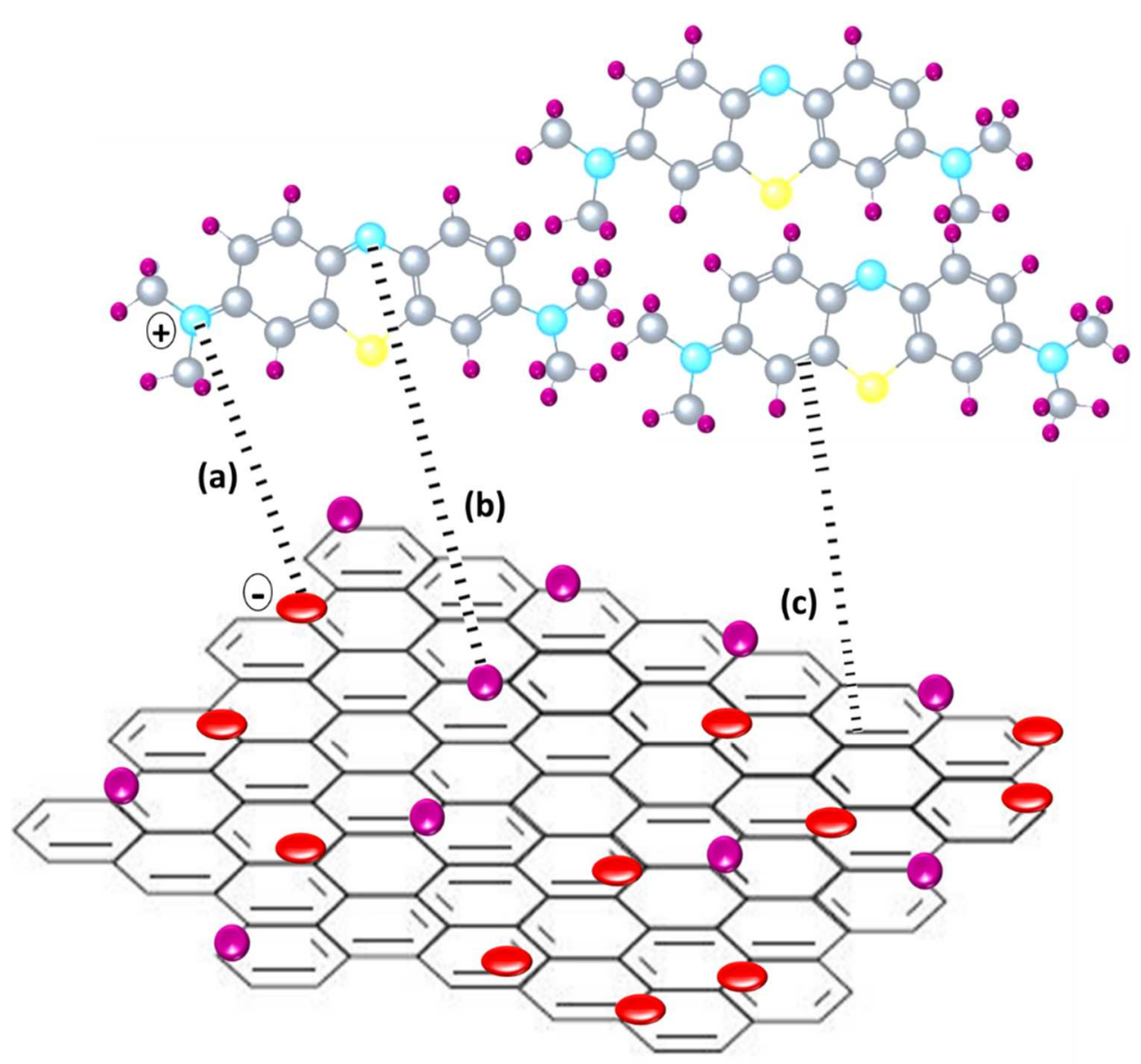

Figure 13 Schematic representation of MB adsorption on the fGNP1 surface: (red: oxygen); (purple: hydrogen) ;(blue: nitrogen);(yellow: sulfur). 


\section{Conclusion}

This work investigates graphene nanoplatelets of high structural quality; this carbon nanomaterial is seldom studied for its ability to adsorb pollutants. A challenge resides in the success of functionalization for their facile dispersion in aqueous medium. The occurrence of functionalization at the external layers of our graphene nanoplatelets was evidenced by means of several complementary characterization methods. The applied chemical method which allows grafting oxygen-containing functional groups at the graphene surface is quite simple. Their facile dispersion in water offers favorable conditions for an efficient adsorption of methylene blue. The complete parametric study has allowed to better understand the MB/GNP interactions. Adsorption isotherms could be well fitted with the Langmuir model. Also, the best fit was obtained with a pseudo-first-order kinetic model. Interestingly, compared to other carbon nanomaterials, the adsorption capacity related to the respective surface area of these graphene nanoplatelets is significantly higher. Our findings highlight the importance of hydrophobic interactions for dye adsorption already reported in literature. These results suggest that such nanomaterials have a great potential to be used as contaminant adsorbents in wastewater treatment.

\section{Conflicts of interest}

There are no conflicts to declare

\section{Acknowledgments}

The authors would like to thank Lionel Aranda for his help for TGA experiment. They also thank Ms. Nawal Berrada and Dr. Alexandre Desforges for the fruitful discussions. We thank Dr. M. Mallet and Mr. A. Renard from the spectroscopy and microscopy Core Facility of SMI 
LCPME (Université de Lorraine-CNRS-http://www.lcpme.cnr-nancy.fr). The authors thank the French Ambassy in Malaysia for financial support especially for Ms. R. Mohd Firdaus' Fellowship. We acknowledge the financial support given by the Ministry of Education Malaysia through Universiti Sains Malaysia-NanoMITE (203/PJKIMIA/6720009) and Institute of Postgraduate Studies, Universiti Sains Malaysia.

\section{References}

Achee TC, Sun W, Hope JT, Quitzau SG, Sweeney CB, Shah SA, Habib T, Green MJ (2018) High-yield scalable graphene nanosheet production from compressed graphite using electrochemical exfoliation. Scientific Reports 8 (1):14525. doi:10.1038/s41598-018-32741-3

Ali N, Teixeira JA, Addali A (2018) A Review on Nanofluids: Fabrication, Stability, and Thermophysical Properties. Journal of Nanomaterials 2018:33. doi:10.1155/2018/6978130

Amiri A, Shanbedi M, Ahmadi G, Eshghi H, Kazi SN, Chew BT, Savari M, Zubir MNM (2016) Mass production of highly-porous graphene for high-performance supercapacitors. Scientific Reports 6:32686. doi:10.1038/srep32686

https://www.nature.com/articles/srep32686\#supplementary-information

Banerjee S, Chattopadhyaya MC (2017) Adsorption characteristics for the removal of a toxic dye, tartrazine from aqueous solutions by a low cost agricultural by-product. Arabian Journal of Chemistry 10:S1629-S1638. doi:https://doi.org/10.1016/j.arabjc.2013.06.005

Bradder P, Ling SK, Wang S, Liu S (2011) Dye Adsorption on Layered Graphite Oxide. Journal of Chemical \& Engineering Data 56 (1):138-141. doi:10.1021/je101049g

Chen D, Zhang H, Yang K, Wang H (2016) Functionalization of 4-aminothiophenol and 3aminopropyltriethoxysilane with graphene oxide for potential dye and copper removal. Journal of Hazardous Materials 310:179-187. doi:https://doi.org/10.1016/j.jhazmat.2016.02.040

Chen L, Yang J, Zeng X, Zhang L, Yuan W (2013) Adsorption of methylene blue in water by reduced graphene oxide: Effect of functional groups. Materials Express 3 (4):281-290

Cheng Y, Zhou S, Hu P, Zhao G, Li Y, Zhang X, Han W (2017) Enhanced mechanical, thermal, and electric properties of graphene aerogels via supercritical ethanol drying and high-temperature thermal reduction. Scientific Reports 7 (1):1439. doi:10.1038/s41598-017-01601-x

Dimiev AM, Alemany LB, Tour JM (2012) Graphene oxide. Origin of acidity, its instability in water, and a new dynamic structural model. ACS Nano 7 (1):576-588

Dreyer DR, Todd AD, Bielawski CW (2014) Harnessing the chemistry of graphene oxide. Chemical Society Reviews 43 (15):5288-5301

Ermakov VA, Alaferdov AV, Vaz AR, Perim E, Autreto PAS, Paupitz R, Galvao DS, Moshkalev SA (2015) Burning Graphene Layer-by-Layer. Scientific Reports 5:11546. doi:10.1038/srep11546

https://www.nature.com/articles/srep11546\#supplementary-information 
Gadipelli S, Guo ZX (2015) Graphene-based materials: Synthesis and gas sorption, storage and separation. Progress in Materials 69:1-60. doi:https://doi.org/10.1016/i.pmatsci.2014.10.004

Georgakilas V, Otyepka M, Bourlinos AB, Chandra V, Kim N, Kemp KC, Hobza P, Zboril R, Kim KS (2012) Functionalization of Graphene: Covalent and Non-Covalent Approaches, Derivatives and Applications. Chemical Reviews 112 (11):6156-6214. doi:10.1021/cr3000412

Ghosh S, Bao W, Nika DL, Subrina S, Pokatilov EP, Lau CN, Balandin AA (2010) Dimensional crossover of thermal transport in few-layer graphene. Nature materials 9 (7):555

Guo Y, Deng J, Zhu J, Zhou X, Bai R (2016) Removal of mercury (II) and methylene blue from a wastewater environment with magnetic graphene oxide: adsorption kinetics, isotherms and mechanism. RSC Advances 6 (86):82523-82536

Han S, Liu K, Hu L, Teng F, Yu P, Zhu Y (2017) Superior Adsorption and Regenerable Dye Adsorbent Based on Flower-Like Molybdenum Disulfide Nanostructure. Scientific Reports 7:43599. doi:10.1038/srep43599

Hayyan M, Abo-Hamad A, AISaadi MA, Hashim MA (2015) Functionalization of graphene using deep eutectic solvents. Nanoscale Research Letters 10 (1):324. doi:10.1186/s11671-015-1004-2

He J, Cui A, Deng S, Chen JP (2018) Treatment of methylene blue containing wastewater by a costeffective micro-scale biochar/polysulfone mixed matrix hollow fiber membrane: Performance and mechanism studies. Journal of colloid and interface science 512:190-197

Holkar CR, Jadhav AJ, Pinjari DV, Mahamuni NM, Pandit AB (2016) A critical review on textile wastewater treatments: possible approaches. Journal of environmental management 182:351-366

Hou D, Liu Q, Wang X, Quan Y, Qiao Z, Yu L, Ding S (2018) Facile synthesis of graphene via reduction of graphene oxide by artemisinin in ethanol. Journal of Materiomics. doi:https://doi.org/10.1016/j.jmat.2018.01.002

Hu Y, Guo T, Ye X, Li Q, Guo M, Liu H, Wu Z (2013) Dye adsorption by resins: effect of ionic strength on hydrophobic and electrostatic interactions. Chemical Engineering Journal 228:392-397

Johnson DW, Dobson BP, Coleman KS (2015) A manufacturing perspective on graphene dispersions. Current Opinion in Colloid \& Interface Science 20 (5):367-382. doi:https://doi.org/10.1016/j.cocis.2015.11.004

Kabiri S, Tran DN, Cole MA, Losic D (2016) Functionalized three-dimensional (3D) graphene composite for high efficiency removal of mercury. Environmental Science: Water Research \& Technology 2 (2):390-402

Kaya NS, Yadav A, Wehrhold M, Zuccaro L, Balasubramanian K (2018) Binding Kinetics of Methylene Blue on Monolayer Graphene Investigated by Multiparameter Surface Plasmon Resonance. ACS Omega 3 (7):7133-7140. doi:10.1021/acsomega.8b00689

Khan S, Malik A (2014) Environmental and health effects of textile industry wastewater. In: Environmental deterioration and human health. Springer, pp 55-71

Kushwaha AK, Gupta N, Chattopadhyaya MC (2017) Adsorption behavior of lead onto a new class of functionalized silica gel. Arabian Journal of Chemistry 10:S81-S89. doi:https://doi.org/10.1016/j.arabjc.2012.06.010

Lagergren S (1898) Zur theorie der sogenannten adsorption geloster stoffe. Kungliga svenska vetenskapsakademiens Handlingar 24:1-39

Lan Huong PT, Tu N, Lan H, Thang LH, Van Quy N, Tuan PA, Dinh NX, Phan VN, Le A-T (2018) Functional manganese ferrite/graphene oxide nanocomposites: effects of graphene oxide on the adsorption mechanisms of organic $\mathrm{MB}$ dye and inorganic $\mathrm{As}(\mathrm{v})$ ions from aqueous solution. RSC Advances 8 (22):12376-12389. doi:10.1039/C8RA00270C

Li Y-H, Du Q, Tonghao L, Peng X, Wang J, Sun J, Wang Y, Wu S, Wang Z, Xia Y, Xia L (2013a) Comparative study of methylene blue dye adsorption onto activated carbon, graphene oxide, and carbon nanotubes, vol 91. doi:10.1016/j.cherd.2012.07.007

Li Y, Du Q, Liu T, Sun J, Wang Y, Wu S, Wang Z, Xia Y, Xia L (2013b) Methylene blue adsorption on graphene oxide/calcium alginate composites. Carbohydrate polymers 95 (1):501-507 
Liu T, Li Y, Du Q, Sun J, Jiao Y, Yang G, Wang Z, Xia Y, Zhang W, Wang K (2012) Adsorption of methylene blue from aqueous solution by graphene. Colloids and Surfaces B: Biointerfaces 90:197-203

Lv M, Yan L, Liu C, Su C, Zhou Q, Zhang X, Lan Y, Zheng Y, Lai L, Liu X (2018) Non-covalent functionalized graphene oxide (GO) adsorbent with an organic gelator for co-adsorption of dye, endocrinedisruptor, pharmaceutical and metal ion. Chemical Engineering Journal 349:791-799

McKay G, Sweeney AG (1980) Principles of dye removal from textile effluent. Water, Air, and Soil Pollution 14 (1):3-11

Mercier G, Gleize J, Ghanbaja J, Marêché J-Fo, Vigolo B (2013) Soft oxidation of single-walled carbon nanotube samples. The Journal of Physical Chemistry C 117 (16):8522-8529

Mohandoss M, Gupta SS, Nelleri A, Pradeep T, Maliyekkal SM (2017) Solar mediated reduction of graphene oxide. RSC Advances 7 (2):957-963. doi:10.1039/C6RA24696F

Nassar NN, Marei NN, Vitale G, Arar LA (2015) Adsorptive removal of dyes from synthetic and real textile wastewater using magnetic iron oxide nanoparticles: thermodynamic and mechanistic insights. The Canadian Journal of Chemical Engineering 93 (11):1965-1974

Novoselov KS, Fal'ko VI, Colombo L, Gellert PR, Schwab MG, Kim K (2012) A roadmap for graphene. Nature 490:192. doi:10.1038/nature11458

Pathania D, Sharma S, Singh P (2017) Removal of methylene blue by adsorption onto activated carbon developed from Ficus carica bast. Arabian Journal of Chemistry 10:S1445-S1451. doi:https://doi.org/10.1016/i.arabjc.2013.04.021

Pérez-Ramírez EE, de la Luz-Asunción M, Martínez-Hernández AL, Velasco-Santos C (2016) Graphene materials to remove organic pollutants and heavy metals from water: photocatalysis and adsorption. In: Semiconductor Photocatalysis-Materials, Mechanisms and Applications. InTechOpen,

Polat EO, Balci O, Kakenov N, Uzlu HB, Kocabas C, Dahiya R (2015) Synthesis of Large Area Graphene for High Performance in Flexible Optoelectronic Devices. Scientific Reports 5:16744. doi:10.1038/srep16744

https://www.nature.com/articles/srep16744\#supplementary-information

Qi C, Zhao L, Lin Y, Wu D (2018) Graphene oxide/chitosan sponge as a novel filtering material for the removal of dye from water. Journal of colloid and interface science 517:18-27

Qi Y, Yang M, Xu W, He S, Men Y (2017) Natural polysaccharides-modified graphene oxide for adsorption of organic dyes from aqueous solutions. Journal of Colloid and Interface Science 486:84-96. doi:https://doi.org/10.1016/i.jcis.2016.09.058

Qiao X-Q, Hu F-C, Tian F-Y, Hou D-F, Li D-S (2016) Equilibrium and kinetic studies on MB adsorption by ultrathin 2D MoS 2 nanosheets. RSC Advances 6 (14):11631-11636

Robati D, Rajabi M, Moradi O, Najafi F, Tyagi I, Agarwal S, Gupta VK (2016) Kinetics and thermodynamics of malachite green dye adsorption from aqueous solutions on graphene oxide and reduced graphene oxide. Journal of Molecular Liquids 214:259-263. doi:https://doi.org/10.1016/j.molliq.2015.12.073

Selen V, Güler Ö, Özer D, Evin E (2016) Synthesized multi-walled carbon nanotubes as a potential adsorbent for the removal of methylene blue dye: kinetics, isotherms, and thermodynamics. Desalination and Water Treatment 57 (19):8826-8838

Shukla AK, Alam J, Alhoshan M, Dass LA, Ali FAA, Mishra U, Ansari MA (2018) Removal of heavy metal ions using a carboxylated graphene oxide-incorporated polyphenylsulfone nanofiltration membrane. Environmental Science: Water Research \& Technology 4 (3):438-448

Stankovich S, Dikin DA, Dommett GH, Kohlhaas KM, Zimney EJ, Stach EA, Piner RD, Nguyen ST, Ruoff RS (2006) Graphene-based composite materials. nature 442 (7100):282

Szlachta M, Wójtowicz P (2013) Adsorption of methylene blue and Congo red from aqueous solution by activated carbon and carbon nanotubes. Water Science and Technology 68 (10):2240-2248

Tahir U, Yasmin A, Khan UH (2016) Phytoremediation: Potential flora for synthetic dyestuff metabolism. Journal of King Saud University-Science 28 (2):119-130

Temkin M, Pyzhev V (1940) Recent modifications to Langmuir isotherms. 
Wei D, Liu Y, Zhang H, Huang L, Wu B, Chen J, Yu G (2009) Scalable synthesis of few-layer graphene ribbons with controlled morphologies by a template method and their applications in nanoelectromechanical switches. Journal of the American Chemical Society 131 (31):1114711154

Yao Y, Xu F, Chen M, Xu Z, Zhu Z (2010) Adsorption behavior of methylene blue on carbon nanotubes. Bioresource technology 101 (9):3040-3046

Yu X, Cheng H, Zhang M, Zhao Y, Qu L, Shi G (2017) Graphene-based smart materials. Nature Reviews Materials 2:17046. doi:10.1038/natrevmats.2017.46

Yusuf M, Elfghi F, Zaidi SA, Abdullah E, Khan MA (2015) Applications of graphene and its derivatives as an adsorbent for heavy metal and dye removal: a systematic and comprehensive overview. RSC Advances 5 (62):50392-50420

Zazouli MA, Azari A, Dehghan S, Salmani Malekkolae R (2016) Adsorption of methylene blue from aqueous solution onto activated carbons developed from eucalyptus bark and Crataegus oxyacantha core. Water Science and Technology 74 (9):2021-2035

Zhao D, Ding Y, Chen S, Bai T, Ma Y (2013) Adsorption of Methylene Blue on Carbon Nanotubes from Aqueous Solutions. Asian Journal of Chemistry 25 (10):5756

Zhao L, Yang S-T, Feng S, Ma Q, Peng X, Wu D (2017) Preparation and Application of Carboxylated Graphene Oxide Sponge in Dye Removal. International journal of environmental research and public health 14 (11):1301. doi:10.3390/ijerph14111301

Zhou X, Zhang Y, Huang Z, Lu D, Zhu A, Shi G (2016) lonic liquids modified graphene oxide composites: a high efficient adsorbent for phthalates from aqueous solution. Scientific Reports 6:38417. doi:10.1038/srep38417 